\title{
REVISITANDO OS CONCEITOS DE CIDADE DIFUSA E ACESSIBILIDADE: RELAÇÕES COM A CIRCULAÇÃO E O AUMENTO DA FROTA DE VEÍCULOS EM CIDADES MÉDIAS DO ESTADO DE SÃO PAULO
}

\author{
REVISITING THE CONCEPTS OF DIFFUSE CITY AND ACCESSIBILITY: \\ RELATIONS WITH CIRCULATION AND THE INCREASE OF VEHICLES \\ FLEET AT MEDIUM-SIZED CITIES OF THE STATE OF SÃO PAULO
}

\author{
Cássio Antunes de Oliveira \\ cassio.antunes@gmail.com \\ Doutorando - Universidade Estadual Paulista
}

\begin{abstract}
RESUMO
Objetiva-se realizar uma análise teórica do conceito de cidade difusa que se traduz em novas formas de urbanização. Concomitante a essa análise se fará também considerações sobre a noção de acessibilidade privilegiando uma de suas dimensões, a circulação. Feitas essas análises teóricas, parte-se para uma breve compreensão do rodoviarismo no Brasil e do papel do automóvel na sociedade brasileira, em razão de ser o principal meio de circulação urbana no país. Por fim será feita uma análise da evolução da frota de veículos e da população de seis cidades médias do Estado de São Paulo, as quais são: Ribeirão Preto, São José do Rio Preto, Bauru, Presidente Prudente, Marília e Araçatuba. Considerando o modo capitalista de produção, portanto, por uma ótica mais econômica, é possível identificar algumas tendências de produção do espaço urbano, além de agravamento dos problemas relacionados ao uso de carros (automóveis) particulares nos deslocamentos nas cidades médias referidas trazendo como exemplo empírico problemas ocorridos na cidade de São José do Rio Preto.
\end{abstract}

Palavras-chave: produção do espaço, cidade difusa, acessibilidade, circulação, cidades médias.

\begin{abstract}
The main objective of this paper is to perform a theoretical analysis of the concept of diffuse city that presents new shape of urbanization. Concomitant to this analysis, it will also be done some considerations about the idea of accessibility benefiting the circulation. From this theoretical analysis, the next step is to weave a brief understanding of road system in Brazil by reason of being the main way of urban circulation in the country. Finally it will be done an analysis of the evolution of the fleet and population in six average cities in state of São Paulo, which are: Ribeirão Preto, São José do Rio Preto, Bauru, Presidente Prudente, Marília and Araçatuba. According the capitalist mode of production, although for a more economic perspective, it is possible to identify some trends in production of urban space, in addition to worsening the problems related to the use of individual car to displacement in medium-sized cities showing as empirical example, problems as occurred in the city of São José do Rio Preto.
\end{abstract}


Keywords: production of the space, diffuse city, accessibility, circulation, mediumsized cities

\section{Introdução}

A produção do espaço urbano é caracterizada pela ação de diferentes agentes sociais com diferentes intencionalidades. No entanto, é possível afirmar que há certa convergência de objetivos ao mesmo tempo em que pode haver diferentes intencionalidades resultando em conflitualidades. Desta forma, a cidade do ponto de vista dos processos e da forma, revela uma paisagem constantemente transformada. Os modos de produção também exercem influência nessa produção espacial. Para esse texto será considerado o papel do modo capitalista de produção nas intencionalidades dos principais agentes sociais que produzem e modificam a cidade. Porém, compreendese que em razão de ser uma produção social, a cidade está em constante mudança, razão pela qual se torna sempre um desafio à busca pela compreensão dos fenômenos que ocorrem e modificam o espaço urbano.

Na busca pela compreensão dos fenômenos urbanos reconhece-se que há várias dimensões que são interelacionadas, como a espacial, cultural, econômica, política etc. No entanto as reflexões a serem feitas nesse texto dará mais foco as dimensões econômica, cultural e espacial que terão mais vulto em detrimento de outras dimensões não menos importantes.

Uma das dimensões das quais se pode iniciar análises de problemáticas urbanas é a econômica, principalmente na atualidade, uma vez que no modo capitalista de produção dois agentes são os principais produtores ou influenciadores das decisões que produzem dinâmicas que promovem transformações espaciais. Esses agentes são o Estado e os agentes econômicos privados. A ação desses dois agentes pode ocorrer de forma "combinada" ou não. Ocorre de forma "combinada", por exemplo, quando o poder público municipal (Estado) constrói ou revitaliza vias de circulação com objetivo de atender demanda de empresas para instalação de unidades produtivas, ou para o setor de serviços instalarem seus empreendimentos (BOTELHO, 2007). Há outros agentes produtores do espaço urbano, como, por exemplo, bairros populares onde ocorre a 
autoconstrução, ou mesmo as pessoas que residem e constroem favelas (KOWARICK, 2010).

Nesse sentido, objetiva-se nesse texto analisar de uma perspectiva teórica conceitos que tem força explicativa das transformações do espaço urbano no período contemporâneo. O conceito de cidade difusa será discutido do ponto de vista teórico, principalmente, a partir das reflexões de Indovina (2004) e também a cittá difusa (cidade difusa) conforme Secchi (2004).

Outro conceito será importante para a compreensão das transformações do espaço urbano, o de acessibilidade. Relacionado à cidade difusa e a acessibilidade será feita uma análise, a partir de dados secundários, do aumento da frota de veículos da cidade de São Paulo e de cinco cidades médias do Estado de São Paulo: Araçatuba, Marília, Ribeirão Preto, São José do Rio Preto e Presidente Prudente e também da cidade de São Paulo. Serão feitas também breves considerações sobre o automóvel como fetiche social e da opção pelo modal rodoviário como principal meio de transporte no Brasil.

Com dados de aumento da frota de veículos do Estado de São Paulo, de sua capital, São Paulo e de cidades médias do interior, é possível relacionar o aumento significativo do número de veículos novos que entram em circulação com os problemas de falta de espaço para automóveis, engarrafamentos, poluição, desvalorização do transporte coletivo etc. Esses dados de evolução da frota de veículos serão comparados com a evolução da população desses municípios. Paralelamente também serão feitas considerações sobre a importância dada ao modal rodoviário no Brasil ao longo do século XX.

Há uma tendência de agravamento em relação ao transporte por veículos na cidade de São Paulo e nas cidades médias do estado. Trata-se do aumento constante do número de novos veículos que entram em circulação diariamente nas cidades brasileiras. Com as facilidades de obtenção de crédito vive-se um período histórico amplamente favorável à aquisição de veículos, sejam novos ou usados. Este fato poderá num curto prazo tornar o deslocamento e a mobilidade nas áreas metropolitanas, principalmente as 
que possuem papel de centros, ainda mais agravados, principalmente, para os veículos de grande porte destinados ao transporte de carga $\mathrm{a}^{\mathrm{i}}$.

Algumas cidades de porte médio do Estado de São Paulo possuem um número relativamente elevado de veículos por habitante. Mas, a situação é mais preocupante pelo fato de que diariamente é registrado um número também elevado de veículos. Assim, é possível afirmar que a situação do trânsito congestionado e falta de estacionamentos nessas cidades tende a se agravar cada vez mais. Em são Paulo na área central encontra-se prédios de dois, três ou mais andares serem totalmente utilizados como estacionamentos para veículos, o que revela que o crescimento do número de automóveis que circulam na referida área da cidade é muito alto.

\section{A cidade, a acessibilidade e as atividades econômicas}

A cidade é um fenômeno social, espacial, cultural, e após a decadência do feudalismo tem concentrado cada vez mais pessoas, por essa razão entendê-la é um desafio permanente. No entanto, essa separação em dimensões é apenas uma forma didática de compreendê-la, pois na verdade essas dimensões são imbricadas.

A cidade transformou-se, pois passou a ter, para o modo capitalista de produção, como uma de suas funções a de concentradora da produção de necessidades, um local de pulsação, centro de produção, consumo e de controle territorial (poder político) (LEFEBVRE, 1972). Nesse sentido, ao mesmo tempo em que a cidade foi um elemento importante para o desenvolvimento do modo capitalista de produção, esse modo de produção foi importante para desenvolver a cidade e expandir a urbanização.

No processo de superação do modo feudal de produção as cidades receberam inúmeros escravos que fugiam de seus senhores e buscavam abrigo nas cidades. Assim, concomitante a esse evento houve uma intensificação das feiras e evidentemente das trocas e a cidade passou a ter outras funções além das de concentradora de poder político, de artesãos e de garantidora de segurança (LEFEBVRE, 1972). Esse desenvolvimento da cidade promoveu aumento das relações entre as cidades requerendo também avanços nos meios de se realizar essas relações: vias e meios de transporte, 
moedas etc. É possível afirmar que essa demanda gerada pelas transformações referidas engendrou as condições (necessidades de deslocamentos de pessoas e mercadorias) para o desenvolvimento das formas de acessibilidade e de interações espaciais.

Todas essas transformações citadas contribuíram para o aumento do número de cidades na Europa e na América (além de outras partes do mundo) e torná-la um espaço muito apto a concentrar produção e pessoas. Com o desenvolvimento tecnológico das duas revoluções industriais e a criação de determinadas máquinas e disseminação de determinadas fontes de energia como o trem de ferro, automóveis, carvão, petróleo e eletricidade as condições para o aumento da circulação de pessoas e mercadorias por via terrestre foi potencializada. No último quartel do século XIX em diferentes lugares da Europa e nos Estados Unidos foram aperfeiçoados os primeiros exemplares dos automóveis no mundo ii. Para Sávio (2010),

Os automóveis, por sua própria natureza, são largos consumidores de fontes naturais de energia e de recursos financeiros. Todos os anos, acidentes relacionados a ele geram milhões de vítimas em todo o planeta. No entanto, o automóvel ainda continua no centro de todas as nossas projeções de futuro e representa o mais cobiçado objeto de consumo das sociedades modernas, bem como a maior e mais poderosa das indústrias de nosso tempo (SÁVIO, 2010, p. 193).

Assim, com a disseminação do automóvel nas cidades os espaços urbanos tiveram que ser modificados com vistas a se readequar a circulação desse novo objeto em suas vias de circulação. No caso do Brasil juntamente a disseminação do uso do automóvel e da abertura de milhares de quilômetros de estradas com mais vigor a partir da década de 1950 do século XX também houve um processo de urbanização e consequentemente crescimento vertiginoso de muitas cidades. Esses dois fatos redundaram em problemas de ordenamento das cidades, além das readequações nas cidades mais antigas para a circulação dos carros, também os problemas com o aumento das periferias e favelas.

Assim, a urbanização é um processo dinâmico, uma vez que passa por transformações em períodos curtos de tempo e associados a esses processos há outros Geo UERJ. Rio de Janeiro - Ano 16, nº. 25, v.2, $2^{\circ}$ semestre de 2014, pp.324-365 
relacionados à forma (morfologia) e aos conteúdos urbanos. Um desses processos em curso em algumas cidades italianas é o de cidade difusa, conforme constatação de Indovina (2004), no Brasil possivelmente ocorre esse processo na região Metropolitana de Campinas, porém uma afirmação mais contundente requer estudos mais aprofundados que fogem ao objetivo desse trabalho. Será feita adiante uma reflexão sobre o conceito de cidade difusa para que se possa mais adiante relacionar com os conceitos de acessibilidade e, assim, com o meio de transporte mais utilizado nas cidades brasileiras o automóvel.

Seguindo nas reflexões se fará uma leitura do conceito de acessibilidade para mais adiante se discutir a opção pelo rodoviarismo no Brasil e fazer reflexões sobre o carro como um objeto de desejo e nas formas que está inserido na sociedade consequentemente nas cidades. Há uma relação intrínseca entre a acessibilidade e a "lógica" do modo capitalista de produção, uma vez que, se nesse modo de produção o principal objetivo dos agentes produtivos é a acumulação, o aumento do consumo e da velocidade de circulação do capital passou a ser de extrema importância. Para se compreender na produção do espaço urbano as formas de deslocamentos, sejam de pessoas, mercadorias ou informações há dois conceitos que são primordiais o de acessibilidade e o de circulação. Porém, se dará mais ênfase ao de acessibilidade, em razão de não se restringir especificamente aos deslocamentos, mas também a rapidez em ter acesso às necessidades.

Para Camagni (2005) a acessibilidade urbana ou o "princípio da acessibilidade" [...] ecuentra em la base de la organización interna del espacio urbano e nace de la competência entre las diversas actividades económicas para asegurarse las localizaciones más vantajosas (CAMAGNI, 2005, p. 51). Apresentado o contexto em que se assenta o princípio da acessibilidade pode-se apresentar seu significado,

[...] superar la barrera impuesta por el espacio al movimiento de personas y cosas y al intercambio de bienes, servicios e informaciones. Accesibilidad significa rápida disponibilidad de factores de producción y bienes intermédios para la empresa, sin tener que soportar un tiempo/coste de transporte; significa posibilidad de recoger información estratégica com una ventaja temporal respecto a los competidores; significa para las

Geo UERJ. Rio de Janeiro - Ano 16, no. 25, v.2, $2^{\circ}$ semestre de 2014, pp.324-365

ISSN: 1415-7543 E-ISSN: 1981-9021

http://www.e-publicacoes.uerj.br/index.php/geouerj 
personas, poder disfrutar de servicios infrecuentes, vinculados a localizaciones específicas (museos, obras de arte, bibliotecas, teatros), o de la cercania a maravillas específicas de la naturaleza sin tener que incurrir em costes de grandes desplazamientos (CAMAGNI, 2005, p. 51).

Conforme se pode constatar muitas das demandas geradas pela urbanização e pela industrialização, que são dois processos interligados, são relacionadas com o princípio da acessibilidade. Há que se fazer um esclarecimento em relação a essas características apresentadas por Camagni (2005) como explicativas para a noção de acessibilidade. Não se compreende a realidade como etapista em que há um observador que ao constatar os problemas parte na busca de soluções e, assim, ao perceber tais demandas "cria" a acessibilidade e a torna real. Na verdade, compreende-se a produção do espaço como um processo dinâmico em que as necessidades e intencionalidades dos agentes surgem, ou emergem, e são superadas/resolvidas sem que, necessariamente, haja uma combinação entre os agentes.

Outra preocupação em relação à forma em que se compreende os processos destacados por Camagni (2005) é a relacionada ao período em que ocorreram. Por exemplo, a circulação de pessoas e mercadorias existe no espaço intraurbano desde que se formaram as cidades e eram feitas por meios de transporte como carroças e posteriormente por bondes, trens/locomotivas (no caso das locomotivas esse deslocamento ocorria principalmente entre as cidades) e só posteriormente no século XX é que houve a difusão do automóvel (SÁVIO, 2010). O importante a reter dessas considerações é que a acessibilidade, da mesma forma que a segregação, pode ser compreendida mais como um processo do que como um fato, por isso, mesmo que suas determinantes mudem não necessariamente implica no seu fim (SPOSITO, 2012) ${ }^{\mathrm{iii}}$.

Analisar o espaço urbano considerando a acessibilidade não se restringe a considerá-la apenas como as formas de conexão pelas pessoas entre espaços intraurbanos e interurbanos e também como formas de contornar as fricções espaciais, tornando o espaço mais fluido ${ }^{\text {iv }}$. A acessibilidade contribui para o estudo dos fenômenos urbanos com muito mais vigor se relacionada com outras infraestruturas, redes e as intencionalidades dos agentes sociais vigentes no período analisado. 
Feitas essas considerações a respeito da acessibilidade, prosseguir-se-á nas reflexões sobre produção do espaço urbano. A cidade é concentradora da produção, conforme a distinção feita por Lefebvre (1972) que a compreende a partir de dois sentidos. A primeira oriunda dos textos de Marx e Engels, que a concebem a partir da filosofia, para os quais,

Produção significa criação e engloba a arte, a ciência, as instituições e o próprio Estado, bem como as actividades geralmente denominadas "práticas". A divisão do trabalho, que fragmenta a produção e faz com que o processo escape à consciência, é também produção, como o são a consciência e a linguagem. A natureza, por sua vez transformada, é produzida; o mundo sensível que parece dado, é criado (LEFEBVRE, 1972).

Devido à necessidade de se deslocar para realizar as diversas atividades desenvolvidas pelas pessoas nas cidades, o homem ao longo do tempo criou e adaptou formas e meios para circular e acessar os lugares que necessitava. Assim, a partir dessa concepção de produção é possível compreender que as melhorias nas formas de circular e se deslocar o homem potencializou a produção. A análise da produção do espaço urbano, principalmente a partir do século XX, é indissociável da consideração da circulação, acessibilidade e das interações espaciais.

A acessibilidade não está relacionada apenas a distância do centro, mas ao meio de deslocamento utilizado pelas pessoas e pelas vias de circulação disponíveis pelas áreas que necessita percorrer/acessar. Assim, a acessibilidade depende da renda e consequentemente da capacidade de apropriação de solo e de meios de deslocamento (automóveis).

Devido a esses fatores um bairro popular localizado na periferia de uma cidade pode significar muitas dificuldades de acessibilidade a seus moradores ao centro, em razão de não ser interligado ao centro por vias de circulação rápidas (vias expressas). Um condomínio fechado localizado a mesma distância que o referido bairro popular, ocupado por pessoas com rendas altas pode possuir condições de acessibilidade ao centro em condições muito melhores (por ser ligado ao centro por vias expressas e em 
razão de a maioria desses moradores possuírem automóveis) ${ }^{\mathrm{v}}$. No caso desse exemplo o principal diferencial para a acessibilidade é a renda econômica. $\mathrm{O}$ fato de os dois casos desse exemplo se localizarem em áreas distantes do centro econômico que pode ser chamado de periferia desmistifica a identificação dos bairros localizados nas bordas da cidade como sendo os habitados por pessoas menos favorecidas economicamente ${ }^{\mathrm{vi}}$.

O conceito de acessibilidade passou por redefinições ao longo do tempo e a concepção atual tem como característica a forma em que o espaço é compreendido que é diferente da forma em que alguns autores clássicos o consideravam, uma vez que para von Thünen, por exemplo, o espaço era visto como uma planície isotrópica. Mas isto não significa que as contribuições de von Thünen não foram relevantes, mas que houve prosseguimento nos seus estudos. Na verdade, uma das principais condicionalidades do conceito é a superação das fricções espaciais, conforme afirmação de Camagni (2005), impostas seja pelas diferenciações espaciais ou mesmo pelas condições econômicas das pessoas.

Não se deve pautar uma análise a partir do conceito de acessibilidade e reduzir os limites explicativos do conceito apenas relacionado com a relação de deslocamento e seus custos. Mas também considerar outros fatores, como por exemplo, a existência de redes de telecomunicações no espaço urbano, a localização e as formas de acesso a equipamentos e áreas para lazer, locais de trabalho e de compras ${ }^{\mathrm{vii}}$.

No caso dos dois bairros utilizados como exemplo a existência de redes de telecomunicações (fibra ótica, cabos para sinais de TV, cobertura para celular) disponíveis para os moradores do condomínio fechado também pode significar melhores condições de acessibilidade.

A acessibilidade é uma das condicionalidades do processo que culmina na cidade difusa, uma vez que as pessoas mudam seus locais de moradia e alguns setores de comércio para áreas periurbanas, em um primeiro momento, em razão de ter ciência de condições significativas de acessibilidade nos novos locais.

Assim, na formação da cidade difusa há considerações em relação à acessibilidade em razão da relação entre essas novas formas de produção da cidade e os deslocamentos no espaço urbano. Para Indovina (2004), 
En uma gran ciudad una plobación numerosa de aceder facilmente a cada punto do território definido. En una gran ciudad una plobación tiene posibilidad de fácil acceso (en términos físicos) a cada punto de la ciudad. Evidentemente, se trata de una accesibilidad muy diferenciada; a nível tecnológico se puede distinguir entre uma accesibilidad peatonal e una mecânica (según vários medios) desde el punto de vista administrativo, pueden existir unos limites; desde el punto de vista económico-social, se pueden presentar situaciones de exclusividade, etc.; de todos modos el punto de vista que predomina en las consideraciones relativas a la ciudad es la accesibilidad medida em términos de multiplicidad de ocasiones y de proximidad. Desde este punto de vista resulta máxima la distancia entre la ciudad tradicional y la ciudad difusa: en la segunda, la plobación se presenta fuertemente penalizada en términos de accsesibilidad física (INDOVINA, 2004, p. 54).

A partir das condições de acessibilidade aos locais e de suas condições econômicas que o agente econômico procura e escolhe o local da localização mais vantajosa na cidade. A partir do século XX e com ainda mais intensidade no século XXI o principal meio para se deslocar no espaço intraurbano é o veículo automóvel (carro, ônibus, micro-ônibus caminhões, camionetas, caminhonete). O próximo item objetiva realizar uma leitura do conceito de cidade difusa mais adiante se fará uma análise do carro e sua influência no cotidiano das pessoas e, consequentemente das cidades, e dos problemas que existem devido às tendências de aumento das frotas de veículos municipais.

\section{Revisitando o conceito de cidade difusa}

A cidade no período medieval era bastante concentrada e ainda cercada por muros em razão de servir também como um reduto de segurança ${ }^{\text {viii }}$. Esta característica da cidade concentrada permaneceu de forma mais acentuada até por volta dos séculos XI, e XII período em que começou um processo de renascimento urbano em razão do revivescimento do comércio no Mediterrâneo que desempenhou papel importante no comércio transcontinental (DOBB, 1973). 
Feitas essas considerações iniciais é possível estabelecer relações entre a morfologia das cidades medievais com as contemporâneas considerando as novas tendências de processos e de morfologia urbana, como é o caso da cidade difusa. $\mathrm{Na}$ atualidade há transformações que apontam para a produção da cidade difusa, ou seja, apresenta uma morfologia diferente da característica da cidade medieval, que era mais concentrada.

A morfologia urbana foi estudada de forma mais aprofundada por Capel (2002) e contribuiu para o estudo da cidade difusa, uma vez que "los aspectos fundamentales del estúdio geográfico de la morfologia han sido el plano, los edifícios, los usos del suelo y el estúdio morfológico integrado de áreas concretas de la ciudad" (CAPEL, 2002, p. 22). Assim, no estudo da produção do espaço urbano a consideração desses dois conceitos contribui significativamente para a análise.

O conceito de cidade difusa foi elaborado por Francesco Indovina para analisar transformações no espaço urbano de cidades italianas. Indovina (2004) elencou três características dos territórios em que estudou a cidade difusa na Itália: cidades inseridas em um espaço agrícola; cidades rodeadas por campo urbanizado (ou seja, campo com edificação disseminada, residencial e não residencial); uma única grande cidade com algumas zonas de campo incorporada nelas. Cada uma dessas características são reflexos de intencionalidades sociais ou a aparição de exigências de tipo produtivo, enfim são referentes aos ciclos específicos de desenvolvimento econômico e social.

Os conceitos utilizados para se entender as transformações da urbanização e da cidade apresentaram limites, assim há fenômenos distintos que para seu entendimento requerem a formulação de novos conceitos. Assim, antes o adjetivo "difuso" qualificava a urbanização e também é empregado para qualificar a cidade. Urbanização difusa e cidade difusa são fenômenos distintos, embora a cidade difusa tenha uma herança da urbanização difusa. As diferenças residem tanto no marco territorial, quanto no econômico e social (INDOVINA, 2004).

A mobilidade da população é uma das características da formação da cidade difusa. Assim, Indovina (2004) argumenta que as aspirações de parte da população urbana por melhores condições de moradia tem resultado em procura por locais para 
habitação em áreas periurbanas ou mesmo rurais próximas do perímetro urbano. Outra forma de dinâmica social que contribuiu para a caracterização da cidade difusa é a transformação de hábitos de famílias que possuem vínculos simbólicos com as atividades rurais. Essas famílias incorporam alguns valores urbanos, mas não abandonam os rurais. Desta forma, uma mudança observada é o aumento de residências unifamiliares localizadas em áreas rurais, geralmente seus moradores constroem nas propriedades familiares e nelas residem, mas desenvolvem atividades secundárias (INDOVINA, 2004).

A cidade difusa não se resume apenas em transformações nos valores e nas atividades familiares, mas em outras mudanças. Secchi (2007) apresenta uma síntese dessas mudanças,

Com efeito, a dispersão da cidade, antes de suas periferias, depois ao redor delas e, depois ainda, na cidade difusa, é o que aumenta vertiginosamente a diversidade das situações: a cidade, a cidade difusa principalmente, é ao mesmo tempo, concentração, reinvenção de suas partes mais antigas, modificação das partes modernas, densificação em rarefação, produção de novos lugares centrais de densidade, de proximidade e de distanciamento, de distância e de separação (SECCHI, 2007, p. 118).

Assim, essa diversidade de situações modificam a morfologia urbana. O “desenho" da cidade se redefine numa relação intrínseca com o seu conteúdo, sendo este último marcado pelas intencionalidades sociais.

Secchi (2007) ao analisar a cidade contemporânea e seu projeto afirma que,

Separar e afastar transformou-se no grande paradigma de toda moderna política urbana; produziu bairros, hospitais, escolas e universidades, teatros e estádios, como lugares de alta especialização. Fragmentando a cidade, transformou-a em ilhas, que o higienismo, a técnica dos transportes e a urbanística moderna têm, progressivamente, afastado entre si, imergindo-as em um espaço urbano sempre mais dilatado, apoiando-as em uma grande camada mineral, tendencialmente homogêneo que,

Geo UERJ. Rio de Janeiro - Ano 16, nº. 25, v.2, $2^{\circ}$ semestre de 2014, pp.324-365

ISSN: 1415-7543 E-ISSN: 1981-9021

http://www.e-publicacoes.uerj.br/index.php/geouerj 
como mostra a extraordinária sequência de imagens da cidade americana, tomadas por Alex McLean para Mutation, transformando-as em sedes de novos comportamentos e estilos de vida (SECHI, 2007, p. 125-126).

Sechi (2007) afirma que juntamente com valores sociais que tende a promover separações e afastamentos, fragmentações nos espaços urbanos, como exemplo a especialização de áreas da cidade, destaca ainda que ligado a essas mudanças está à técnica do transporte.

Indovina (2004) afirma ainda que, além das transformações na morfologia urbana relacionadas às moradias, há também as relacionadas às atividades econômicas (industrial e comercial) em razão das dinâmicas de dois processos, em um primeiro momento a reestruturação em um segundo momento a deslocalização. A localização das atividades econômicas, principalmente as industriais, pôde ser redefinida em razão de dois fatores: o primeiro é relacionado ao aumento do custo de manutenção de atividades nas áreas centrais das cidades provocado por proibições, vínculos administrativos e congestionamentos. O segundo é relacionado aos avanços nos sistemas de transporte e de telecomunicações, e de organização produtiva (regime de produção flexível) (HARVEY, 2003).

No Brasil o fenômeno da cidade difusa é menos intenso (ou talvez ainda não ocorra) do que na Europa, mais precisamente, na Itália onde Indovina (2004) fez suas análises. É possível perceber na Região Metropolitana de Campinas por meio de imagens de satélite disponíveis no Google Earth $^{i x}$ uma morfologia urbana nas áreas periféricas das cidades ou nos limites entre os municípios com uma organização espacial que se poderia classificar como cidade difusa. Do ponto de vista dos processos também se pode afirmar que há uma dinâmica produtiva e interacional entre as cidades da referida região que possibilita a cidade difusa. Para Sposito (2004) em partes da aglomeração urbana de Jundiaí há o fenômeno de muitas residências que funcionam como segunda moradia (em geral para habitantes de São Paulo), o mesmo ocorre nas cidades de Vinhedo e Valinhos ${ }^{\mathrm{x}}$. Mas, essas cidades continuam a ter áreas urbanas concentradas e densas. Desta forma, para essas áreas parece mais apropriado falar em descontinuidades (espacial/territorial) urbanas do que em cidade difusa ${ }^{\mathrm{xi}}$.

Geo UERJ. Rio de Janeiro - Ano 16, ${ }^{\circ}$. 25, v.2, $2^{\circ}$ semestre de 2014, pp.324-365

ISSN: 1415-7543 E-ISSN: 1981-9021

http://www.e-publicacoes.uerj.br/index.php/geouerj 
Caiado e Pires (2007) fizeram um estudo em que analisam a expansão recente na Região Metropolitana de Campinas. Para as autoras no recorte espacial mencionado o fenômeno das novas formas de urbanização é compreendido como dispersão da urbanização. Nesse sentido,

O fenômeno da dispersão da urbanização tem sido estudado, no Brasil, a partir da constatação da expansão do tecido urbano com ocupação de áreas isoladas da conurbação principal, com predomínio de baixas densidades, apoiados em diversos sistemas de infraestrutura viária e dotadas de extensos espaços livres. São núcleos de urbanização separados no espaço mas com a manutenção dos vínculos estreito com as demais áreas da cidade, como parte de um único sistema urbano (CAIADO; PIRES, 2007, p. 83).

E mais adiante afirmam que no caso da Região Metropolitana de Campinas,

A circulação entre municípios da região e das aglomerações do entorno, assim como entre a RMC e a RMSP é intensa, com grande número de pessoas circulando em carros particulares, vans ônibus fretados, para ir a universidades, para os seus locais de trabalho e para consumir em shoppings e outros grandes equipamentos comerciais (CAIADO; PIRES, 2007, p. 83).

Desta forma, é possível perceber que entre vários fatores que possibilitam a dispersão urbana estão os meios de transportes que circulam em rodovias, os automóveis. Em razão de ser essa máquina umas das principais responsáveis pelas formas de dispersão da urbanização no próximo item se fará uma análise do carro como um objeto que influencia profundamente a vida nas cidades, ou seja, a produção do espaço urbano influindo nos comportamentos cotidianos das pessoas.

\section{O fetiche pelo carro e a expansão de seu uso e o rodoviarismo no Brasil}

A palavra fetiche significa, resumidamente, no caso do carro um objeto que supostamente tem poderes mágicos ${ }^{\mathrm{xii}}$. A análise sobre o carro considerará também essa 
faceta que o automóvel pode significar para seu proprietário. A história do carro no Brasil começou no ano de 1900, ao ser trazido pelos irmãos Alberto e Henrique-Santos Dumont (SÁVIO, 2010, p. 24) e a partir dessa data as maiores cidades brasileiras como São Paulo e Rio de Janeiro começaram a adaptar seus espaços urbanos públicos e privados, em razão das garagens, para a circulação desse novo meio de transporte. Posteriormente, nos anos 1920 os veículos já haviam ganhado espaço nas cidades brasileiras, conforme afirma Haag (2011),

Ao final dos anos 1920, os veículos passaram a ser os senhores absolutos das ruas e os pedestres eram empecilhos da 'utopia possível', invasores. O passado, histórico reforça, os problemas presentes. Com a chegada do automóvel, esse virou dominante, algo que é coerente com o modelo dos segmentos aristocráticos brasileiros, que, tendo o carro, abandonam o bonde e o trem, reiterando um desdém pelo transporte público [...] (p. 85).

Mais tarde, na década de 1950 durante o governo do ex-presidente Juscelino Kubitschek, é inaugurada a primeira fábrica de automóveis no Brasil, a alemã Volkswagen. Desse período em diante o carro passou a ser o principal meio de transporte no Brasil e consequentemente o transporte rodoviário o modal mais utilizado. As cidades mais antigas foram adaptadas ao longo desse processo e as novas já foram pensadas para esse modo de transporte.

Nesse sentido, no presente há muitas dimensões que envolvem a evolução e o ordenamento da circulação nos espaços urbanos. Dessas, destacar-se-á os interesses das montadoras e consequentemente da cadeia produtiva, comercial e de serviços ligados ao automobilismo, os interesses geral (de toda a população nas suas necessidades de deslocamentos diários) e particular (em que o indivíduo se preocupa exclusivamente com suas necessidades de circulação). Haag (2011) mostra como é possível essa manifestação de individualismo presente no imaginário dos condutores de veículos, assim,

[...] o sinalizador do desejo individual que representa a pressa e a impaciência ao ter o caminho obstruído por uma multidão de 
desconhecidos. Esses outros que não aceitamos como iguais e que são 'obstáculos' em nosso trajeto (p. 82).

Desta forma, é possível perceber que os conflitos de interesses no trânsito das cidades brasileiras não é um fenômeno novo, ou que tenha surgido há poucas décadas. Trata-se de um problema antigo, com o agravante de ter sido potencializado.

Sennett (1988) ao analisar os espaços público e privado, considerando as intencionalidades em algumas construções arquitetônicas e o espaço público da rua afirma que o carro significa para seus condutores e passageiros mais que um meio de transporte, mas uma forma de individualidade,

Não se usa o carro para ver a cidade; o automóvel não é um veículo para se fazer turismo - ou melhor, não é usado como tal a não ser por motoristas adolescentes que saem para dar uma volta de carro sem permissão do dono. Em vez disso, o carro dá liberdade de movimentos; pode-se viajar sem ser interrompido por paradas obrigatórias, como as do metrô, sem mudar a sua forma de movimento, de ônibus metrô, via elevada ou apenas ir do lugar $A$ para o lugar $B$. As ruas da cidade adquirem então uma função peculiar: permitir a movimentação; se elas constrangem demais a movimentação, por meio de semáforos, contramãos, etc., os motoristas se zangam ou ficam nervosos (SENNETT, 1988, p. 28).

Com a valorização dada ao automóvel como meio de circulação e transporte ao longo do século XX, esta máquina tornou-se a responsável por mais de $90 \%$ do transporte de passageiros no Brasil, seja interurbano ou intraurbano, uma vez que apenas em algumas poucas capitais existem serviços de transporte de passageiros por meio de trens e metrôs, como exemplo: São Paulo, Rio de Janeiro, Brasília, Porto Alegre e Belo Horizonte.

Assim, a opção pelo rodoviário também esteve e está, com menos intensidade, assentada em dois fatores principais; um de ordem política, outro de ordem econômica. $\mathrm{O}$ fator político refere-se à vinculação entre modernidade associada ao transporte rodoviário e de atraso ao ferroviário. Politicamente houve um posicionamento, em prol, da suposta "modernidade". Já em relação ao fator econômico é possível afirmar que 
relacionado com essa questão estava à falta de recursos do Estado para realizar a modernização e expansão do transporte ferroviário, em meados do século $\mathrm{XX}$, que carecia de adequação às novas tecnologias para o setor e da regularização das bitolas (BARAT, 1978). Como consequência negativa priorizou-se o rodoviarismo que recebeu incentivos políticos para que as montadoras estrangeiras instalassem unidades no Brasil, principalmente no governo de Juscelino Kubitschek (1956-1960), como exemplos a Ford, Volkswagen e a Chevrolet. Houve, além disso, facilitado pelo deslumbramento provocado pela possibilidade do cidadão de possuir um carro e poder sair dirigindo-o quando quiser e não mais depender de outros meios de deslocamento por meio de ideologia ${ }^{\text {xiii }}$.

Segundo Xavier (2003) os paulistas adotaram uma política rodoviarista que levaram à construção das primeiras estradas modernas do estado. Nas palavras do autor,

A diversificação de fluxos levada a cabo pela crescente urbanização, o fascínio das elites paulistas pelas competições e passeios e a adoção de uma política rodoviarista levaram à construção das primeiras rodovias modernas no Estado de São Paulo, reforçando os laços entre as regiões Sudeste e Sul (p. 332).

O fato de nas paisagens das ruas da maioria das cidades brasileiras existir um número alto automóveis e de este objeto, que é fruto do engenho humano, reinar nas ruas e no planejamento como um "ser" que merece imenso respeito não decorreu apenas de fatores políticos e econômicos. Há também o fator psicológico conforme aponta Xavier (2003).

O fator psicológico atua em favor das montadoras, uma vez que através de seus departamentos de marketing criam ilusões e necessidades para o automóvel além das que supostamente o automóvel tem de fato. Nesse sentido, é interessante analisar as afirmações de Dawson (2006) que escreveu sobre o vício dos Estados Unidos por petróleo, e assim relacionou-o com a fabricação de carros juntamente com uma pequena análise sobre a importância que tem as indústrias de automóvel para o capitalismo, sobretudo para o cidadão norte-americano. 
A análise de Dawson (2006) em muito se relaciona com o contentamento, no Brasil, que a posse de um carro proporciona ao proprietário desde a década de 1920, conforme já citado, visto que nos Estados Unidos acontece o mesmo deslumbramento das pessoas pelo automóvel. Desta forma, o autor compreende que,

[...] convém entender que todos os capitalistas enfrentam aquilo a que chamo "o problema dos produtos". A realidade é que apenas certas coisas dão bons produtos de comércio (também conhecidas como "mercadorias", na expressão de Marx) (DAWSON, 2006, sem paginação).

O carro é um dos melhores, senão o melhor, produto que os capitalistas já inventaram devido ser complexo na sua montagem e com amplas possibilidades de inovação.

Dawson (2006) mais adiante afirma que

[...] produtos que sejam grandes, complexos e sujeitos a reparações e substituições tão frequentes quanto possíveis, dentro dos limites de manter os clientes suficientemente felizes para continuarem a utilizá-los e a comprá-los. Todos os outros factores permanecendo constantes, o quanto maior o produto e mais partes ("partes" pode ser tanto materiais físicos como serviços humanos) tiver o produto, mais oportunidades existem para os capitalistas de controlarem a cadeia de produção a partir da qual eles "fabricam" o seu dinheiro - nomeadamente, ao pagar aos trabalhadores menos do que o valor final dos produtos que os trabalhadores contratados fizeram (sem paginação).

Assim, seguindo no mesmo raciocínio de Dawson (2006), compreende-se que no Brasil a instalação das montadoras de veículos, o pensamento industrializante, a valorização do modal rodoviário e o regozijo em possuir um carro foram os principais condicionantes por se optar pelo rodoviarismo. Por ser a indústria de automóvel altamente dinâmica, o seu produto é factível de constantes inovações que podem ser adicionadas aos veículos sempre que o proprietário desejar. Dentre essas inovações têmse os famosos acessórios (rodas de liga leve, ar condicionado, equipamentos de som e vídeo sofisticados, filmagem de vidros, motores turbo etc.). 
Nesse sentido, Dawson (2006) ao fazer referência à indústria automobilística nos Estados Unidos aponta, também, a necessidade de que para funcionar o automóvel é necessário abastecê-lo e para movimentar é necessário abrir estradas. Nas palavras do autor,

Carros são máquinas fantasticamente grandes e complicadas. Para fabricar, entregar, manter, fazer estradas para eles, segurar, armazenar e abastecê-los nos Estados Unidos exige-se um complexo mega-industrial de mais de um milhão de milhões (trillion) de dólares por ano, dos quais quase todos os elementos são fornecidos por empregados de negócios lucrativos (DAWSON, 2006, sem paginação).

Além dos elementos já citados (acessórios) que torna o veículo um ótimo produto para os capitalistas devido à sua complexidade e alto valor adicionado por produto, há modelos que custam aproximadamente um milhão e meio de reais ${ }^{\text {xiv }}$. De um ano para outro são lançados os mesmos modelos, apenas com pequenas alterações o que pode despertar no comprador a vontade de adquirir um veículo na lógica do "modelo novo". Isto garante, de certa forma, a grande vendagem anual de veículos no Brasil e no mundo. Nessa perspectiva Dawson (2006), compreende que,

A caracteristicamente grande "fetichibilidade" dos carros: através da alteração do tamanho, estilo e dispositivos dos carros, os capitalistas são capazes de extrair um vasto conjunto de métodos para encorajar as pessoas comuns a perceberem os seus automóveis como importantes extensões da sua personalidade (grifo nosso, sem paginação).

Essas características inerentes à cadeia produtiva e ideológica dos automóveis são mais acentuadas hoje do que na década de 1950, quando se iniciou a fabricação/montagem de automóveis no Brasil. Apesar de ser com menor intensidade, mesmo assim, foi muito importante para a consolidação da "vocação" rodoviarista no Brasil. 
Feitas essas considerações, será feita uma análise da frota de veículos em São Paulo e em alguns municípios de porte médio do interior e dos pressupostos ideológicos e políticos que envolvem o transporte rodoviário e os carros.

\section{Evolução da frota de veículos em São Paulo e nas cidades médias do Estado de São Paulo}

A relação entre a ideologia que atua no sentido de valorizar a propriedade de automóveis com a consequência do uso excessivo de espaço público ocupado por eles é expressa nesse apontamento de Haag (2011) que mostra que há,

[...] forte identificação mental e psicológica entre o condutor e o veículo. Isso, aliás, revela o que está na raiz da falta de espaço no trânsito para a circulação de carros que ocupam uma área significativa quando transportam apenas uma pessoa, um supercidadão que fica encastelado em seu mundo. Assim o carro vira um instrumento de projeção da personalidade do seu dono e um índice de ascensão social e capacidade de consumo: uma ofensa ao automóvel equivale a uma ofensa ao seu motorista ( $\mathrm{p}$. $85)$.

Com essa afirmação de Haag (2011) é possível compreender parte dos problemas de violência, desrespeito, entre outros ocorridos no trânsito diariamente, principalmente das cidades médias e grandes. As projeções obtidas por meio de dados como os de frota de veículos nos municípios do Estado de São Paulo apontam para agravamento dessa situação, principalmente em razão de que esses problemas são tratados de forma fragmentada. Uma vez que, a violência no trânsito é de responsabilidade da polícia, os mortos e feridos em acidentes de responsabilidade dos serviços de saúde (públicos e privados), os da qualidade e do planejamento das vias é de responsabilidade dos órgãos fiscalizadores como Departamento de Estradas de Rodagem do Estado de São Paulo (DER-SP), Agência Reguladora de Serviços Públicos Delegados de Transporte do Estado de São Paulo (ARTESP), Agência Nacional de Transportes Terrestres (ANTT), Departamento Nacional de Infraestrutura de Transportes (DNIT), o do ordenamento da cidade, abertura de novas vias para o poder público municipal, o da produção de veículos das montadoras, e o da ideologia fica por 
conta da publicidade, e assim por diante. O mapa 1 mostra a frota de veículos em municípios do Estado de São Paulo. As cidades médias analisadas nesse texto se destacam com suas expressivas frotas.

Mapa 1: Estado de São Paulo: frota de veículos - 2009.

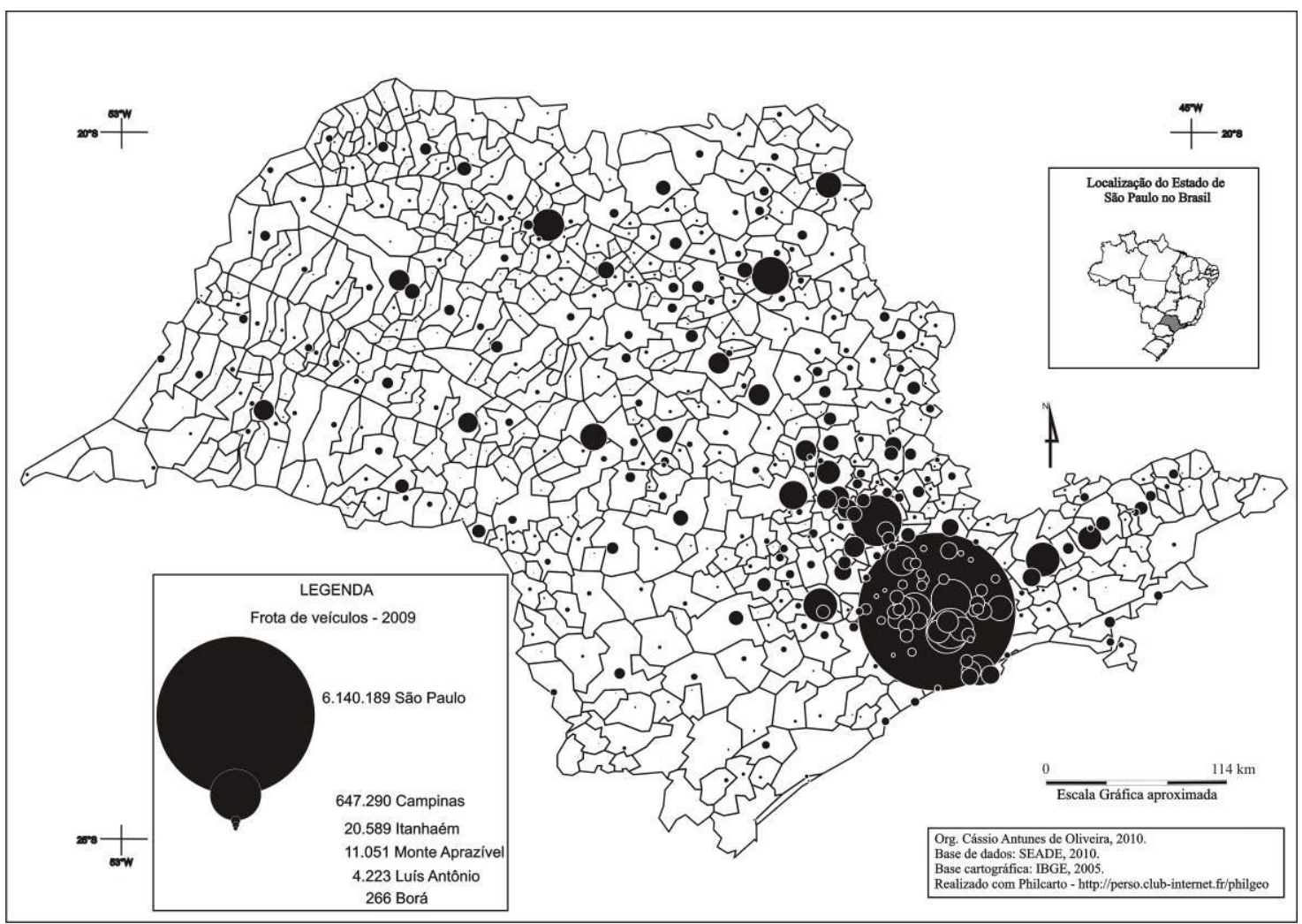

Conforme referido, os primeiros automóveis chegaram ao Brasil no final do século XIX em 1900. Na primeira metade do século XX havia quantidade ainda não muito significativa de automóveis pelas ruas das cidades brasileiras, mas foi na década de 1950 com a vinda de montadoras alemãs e norte-americanas (Volkswagen, Ford e General Motors) para o Brasil que ocorreu o surto rodoviário que aumentou ainda mais nas décadas seguintes. Nesse sentido, objetiva-se fazer uma breve análise da frota rodoviária do Estado de São Paulo considerando que o transporte, a circulação, a mobilidade, a acessibilidade e os deslocamentos estão relacionados de forma bastante intensa à produção do espaço urbano.

\section{Perfil urbano de seis cidades médias do Estado de São Paulo}

Geo UERJ. Rio de Janeiro - Ano 16, no. 25, v.2, $2^{\text {o }}$ semestre de 2014, pp.324-365

ISSN: 1415-7543 E-ISSN: 1981-9021

http://www.e-publicacoes.uerj.br/index.php/geouerj 
Para que a compreensão das reflexões realizadas nesse texto seja mais fácil, a seguir apresenta-se um breve perfil econômico das seis cidades médias analisadas. Essas cidades são investigadas pela Rede de Pesquisadores sobre Cidades Médias (Recime), sendo que para a cidade de Marília há mais informações em razão da publicação de um livro pela Recime sobre essa cidade e Chillán, no Chile. De acordo com Sposito et al (2007) a metodologia para os estudos das cidades médias consideram como dimensão privilegiada a econômica, seguida pela dimensão social considerando também as repercussões relativas ao aprofundamento das desigualdades socioespaciais. É nessa direção que se realizou as análises das cidades paulistas e o perfil urbano delas.

No Brasil o transporte de passageiros é mais de $90 \%$ realizado pelo modal rodoviário e o Estado de São Paulo segue a mesma tendência, apenas a Companhia Paulista de Trens Metropolitanos (CPTM) realiza o transporte de passageiros por meio de trem e metrô, porém restringe-se a Regiões Metropolitanas de São Paulo e alguns municípios do entorno metropolitano, como é o caso de Jundiaí (OLIVEIRA, 2011). Nas cidades do interior do Estado de São Paulo aproximadamente 100\% do transporte de passageiros intraurbano e interurbano é realizado por meios de transporte que utilizam o modal rodoviário. Assim, é possível avaliar que os estudos sobre mobilidade e morfologia urbana que colocam foco nesse fato podem significar contribuições para o entendimento desses problemas e até mesmo no apontamento de soluções. A relação entre transporte urbano, mobilidade, aumento das frotas de veículos em cidades médias tem ainda mais relevância pelo fato de que esse tipo de transporte é quase a totalidade dos tipo de deslocamentos nessas cidades.

As interações espaciais entre essas cidades e os outros municípios do Estado de São Paulo e do Brasil é por meio das rodovias, principalmente o deslocamento de mercadorias. Em relação ao transporte de passageiros, embora não haja linhas ferroviárias de passageiros em nenhuma das seis cidades analisadas, há aeroportos regulares em todas (todos administrados pelo Departamento Aeroviário do Estado de São Paulo - DAESP). No entanto, uma porcentagem baixa de passageiros utiliza o transporte aéreo, se comparado com os deslocamentos por automóveis, sejam carros particulares ou ônibus. 
Em relação aos acessos rodoviários nessas cidades considera-se que são bastante interligadas, uma vez que em cinco das seis cidades há rodovias com pista dupla que cortam suas sedes urbanas, apenas Marília não possui rodovia com pista dupla que liga à sua capital, embora há poucos quilômetros há a rodovia SP 300. Em duas dessas cidades há também uma rodovia federal, a BR 153 que corta os municípios e as sedes urbanas de São José do Rio Preto e de Marília (porém essa rodovia possui pista simples). Todos os municípios tem acesso à capital do estado por rodovias com pista dupla, com exceção de Marília, ainda que todas sejam concedidas à iniciativa privada e tenha a cobrança de pedágio.

A cidade de São José do Rio Preto possui ligação rodoviária para São Paulo por meio da rodovia Washington Luis (310), que tem conexão com o sistema AnhangueraBandeirantes (SP 330 e SP 348). O quadro 1 mostra os principais acessos rodoviários das cidades médias do Estado de São Paulo.

Quadro 1: Estado de São Paulo: acessos (diretos) rodoviários com pista dupla das cidades médias à capital São Paulo e acesso a rodovias federais (diretos).

\begin{tabular}{|c|c|c|c|}
\hline Município & $\begin{array}{l}\text { Rodovia Estadual } \\
\text { com pista dupla }\end{array}$ & Rodovia Federal & Concessão \\
\hline Araçatuba & $\begin{array}{l}\text { Marechal Rondon } \\
\text { (SP 300) }\end{array}$ & - & Sim \\
\hline Bauru & $\begin{array}{l}\text { Marechal Rondon } \\
\text { (SP 300) }\end{array}$ & - & Sim \\
\hline Marília & 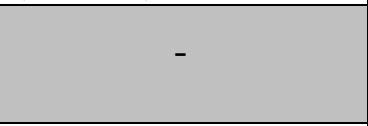 & $\begin{array}{l}\text { Transbrasiliana BR } \\
153\end{array}$ & Sim \\
\hline $\begin{array}{l}\text { Presidente } \\
\text { Prudente }\end{array}$ & $\begin{array}{l}\text { Raposo Tavares (SP } \\
\text { 270)/Castelo } \\
\text { Branco (SP 280) }\end{array}$ & - & Sim \\
\hline Ribeirão Preto & $\begin{array}{l}\text { Anhanguera (SP } \\
\text { 330)/Bandeirantes } \\
\text { (SP 348) }\end{array}$ & - & Sim \\
\hline $\begin{array}{c}\text { São José do Rio } \\
\text { Preto }\end{array}$ & $\begin{array}{l}\text { Washington Luis } \\
\text { (SP } \\
\text { 310)/Anhanguera- } \\
\text { Bandeirantes } \\
\text { 330 e SP 348) }\end{array}$ & $\begin{array}{l}\text { Transbrasiliana BR } \\
153\end{array}$ & Sim \\
\hline
\end{tabular}

Fonte: DER-SP, 2014.

Geo UERJ. Rio de Janeiro - Ano 16, nº. 25, v.2, $2^{\circ}$ semestre de 2014, pp.324-365

ISSN: 1415-7543 E-ISSN: 1981-9021

http://www.e-publicacoes.uerj.br/index.php/geouerj 
Os acessos rodoviários entre as cidades médias podem ser feito, no caso de São José do Rio Preto, Araçatuba, Presidente Prudente e Bauru, por meio das rodovias Assis Chateaubriand (SP 225) e Transbrasiliana (BR 153) que cortam o Estado de São Paulo na posição perpendicular em relação às rodovias radias, que ligam as cidades do interior a capital, seguindo os traçados das linhas ferroviárias do século XIX e XX. Apenas a rodovia SP 425 não possui cobrança de pedágio. As ligações rodoviárias à cidade de Ribeirão Preto e as outras cinco cidades médias são por meio de outras rodovias perpendiculares, ou seja, que cortam o Estado de São Paulo no sentido Norte - Sul, ou vice-versa. O mapa 2 mostra a localização das seis cidades no Estado de São Paulo juntamente com a localização das rodovias no estado.

Mapa 2: Estado de São Paulo localização das cidades de Araçatuba, Bauru, Marília, Presidente Prudente, Ribeirão Preto e São José do Rio Preto.

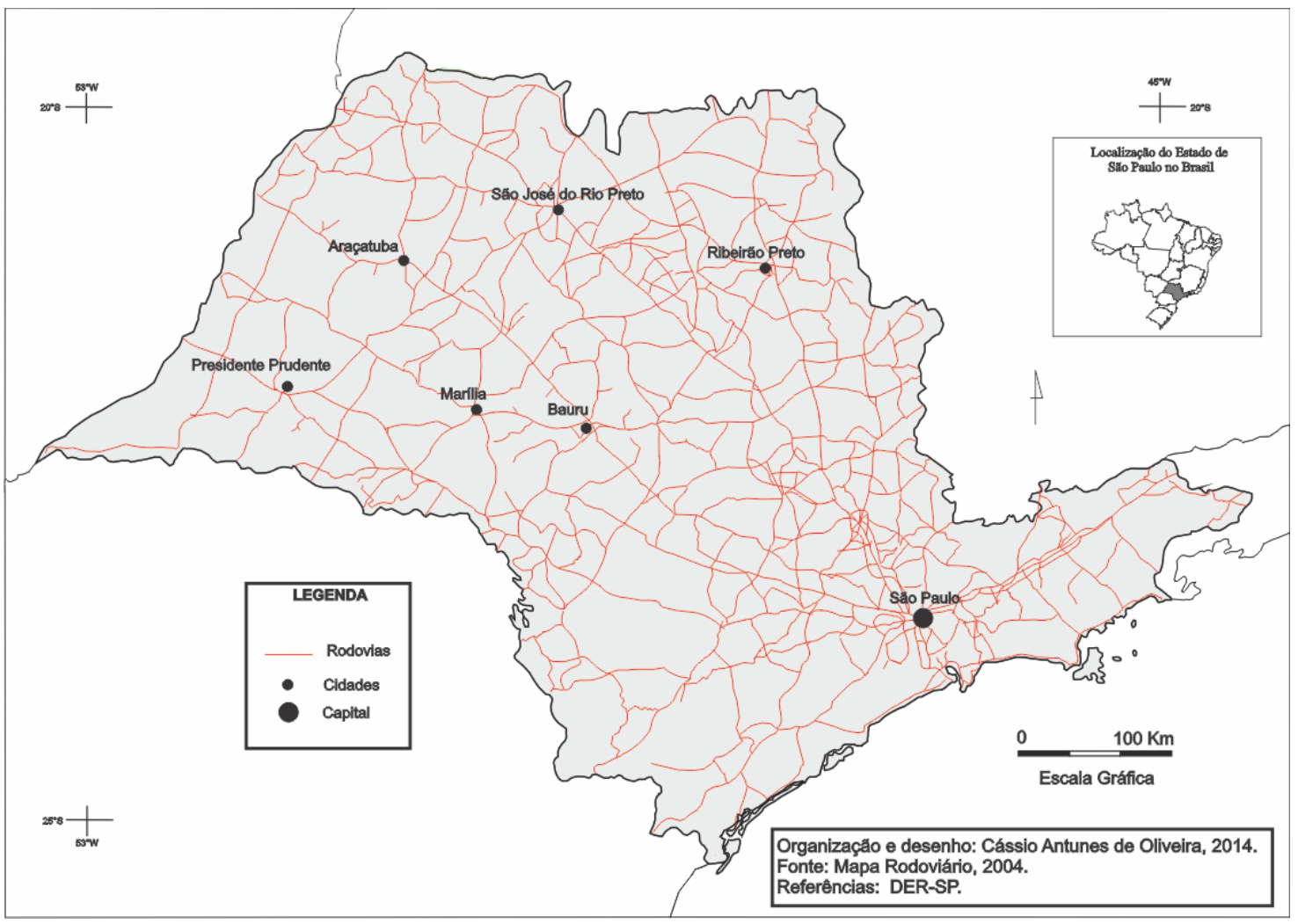

A condição dessas cidades como "cidades médias" significam que elas possuem destaque na rede urbana brasileira e do Estado de São Paulo. As cidades médias Geo UERJ. Rio de Janeiro - Ano 16, no. 25, v.2, $2^{\circ}$ semestre de 2014, pp.324-365 
possuem uma gama de funções urbanas, sendo as principais as relacionadas aos serviços, o que se traduz em afluxo diário de muitos veículos das cidades da região de influência para essas cidades médias. Essas cidades possuem especialidades médicas, universidades e escolas técnicas, hipermercados e shopping centers, salas de cinema, estádios de futebol, aeroportos, agências bancárias e delegacias da Polícia Federal, mais opções de linhas e de horários de ônibus para outras cidades e para a capital do Estado.

Em relação às ligações ferroviárias os seis municípios possuem ligação com a capital do Estado e consequentemente ao Porto de Santos, na verdade, a origem dos centros urbanos ocorreu em razão da dinâmica ferroviária nos século XIX e em alguns municípios no início do século XX, como é o caso de Marília, Presidente Prudente, Araçatuba e São José do Rio Preto (MONBEIG, 1984).

Compreender a noção de cidades médias requer que se tenha conhecimento também de rede urbana. Assim, caracterizar cidades médias e a rede urbana é uma tarefa difícil em razão da dinâmica territorial, conforme destaca Melazzo (2012),

Mesmo em estados da federação onde a rede urbana aparece de maneira mais densa e articulada, o que poderia induzir a considera-la também como consolidada, a exemplo de São Paulo, não deixa de ser notável como as citadas novas configurações territoriais permanentemente definem e redefinem as dinâmicas da divisão territorial do trabalho. E como, a partir delas, alteram papéis, funções, conteúdos e formas das cidades, em suas múltiplas escalas de relações, que articulam o intraurbano, o regional, o nacional e o global.

Assim, no perfil urbano das cidades médias analisadas (ver quadro 2) nesse texto podem também ocorrer modificações em períodos de tempo curto, porém devido a serem cidades que possuem uma importância regional significativa é mais provável que tais mudanças sejam no sentido de dinamização econômica e crescimento. A noção de crescimento não significa que do ponto de vista da funcionalidade dessas cidades seja sempre benéfico. É possível observar de diferentes óticas, e no caso de aumento excessivo da frota de veículos, por exemplo, pode ser agravamento aumento de problemas de mobilidade. 
A seguir apresenta-se uma breve caracterização das seis cidades analisadas em relação a alguns indicadores e uma análise sucinta de suas principais funcionalidades na rede urbana.

Quadro 2: Perfil urbano e econômico de seis cidades médias do Estado de São Paulo

\begin{tabular}{|c|c|c|c|c|c|c|c|c|}
\hline Município & $\begin{array}{c}\text { População } \\
\text { (2014) }\end{array}$ & $\begin{array}{c}\text { Grau de } \\
\text { urbanização } \\
\text { (Em \%) }\end{array}$ & IDHM & $\begin{array}{c}\text { PIB } \\
\text { (2011) }\end{array}$ & $\begin{array}{c}\text { PIB per } \\
\text { capita } \\
\text { (2011) }\end{array}$ & $\begin{array}{c}\text { Participação } \\
\text { da } \\
\text { Agropecuária } \\
\text { no Total do } \\
\text { Valor } \\
\text { Adicionado } \\
\text { (Em \%) } \\
\text { (2011) }\end{array}$ & $\begin{array}{c}\text { Participação } \\
\text { da Indústria } \\
\text { no Total do } \\
\text { Valor } \\
\text { Adicionado } \\
\text { (Em \%) } \\
\text { (2011) }\end{array}$ & $\begin{array}{c}\text { Participação } \\
\text { dos Serviços } \\
\text { no Total do } \\
\text { Valor } \\
\text { Adicionado } \\
\text { (Em \%) } \\
(\mathbf{2 0 1 1})\end{array}$ \\
\hline Araçatuba & 185.509 & 98,07 & 0,788 & $3.901,47$ & $21.380,97$ & 2,69 & 18,70 & 78,61 \\
\hline Bauru & 352.654 & 98,33 & 0,801 & $7.972,31$ & $23.047,15$ & 0,30 & 20,17 & 79,53 \\
\hline Marília & 223.002 & 95,51 & 0,798 & $4.339,88$ & $19.217,43$ & 0,99 & 21,99 & 77,02 \\
\hline $\begin{array}{c}\text { Presidente } \\
\text { Prudente }\end{array}$ & 213.313 & 97,96 & 0,806 & $4.499,98$ & $21.541,33$ & 0,63 & 19,14 & 80,23 \\
\hline $\begin{array}{c}\text { Ribeirão } \\
\text { Preto }\end{array}$ & 638.796 & 99,72 & 0,800 & $18.498,18$ & $30.208,71$ & 0,32 & 18,17 & 81,50 \\
\hline $\begin{array}{c}\text { São José } \\
\text { do Rio } \\
\text { Preto }\end{array}$ & 425.716 & 93,93 & 0,797 & $9.731,33$ & $23.607,19$ & 0,38 & 17,11 & 82,51 \\
\hline
\end{tabular}

Fonte: SEADE, 2014.

A comparação entre os indicadores mostra que as seis cidades possuem certa semelhança em relação a Grau de Urbanização, Produto Interno Bruto (PIB), PIB per capita, Participação da Agropecuária no Total do Valor Adicionado, Participação dos Serviços no Total do Valor Adicionado, Participação da Indústria no Total do Valor Adicionado. Em relação à Participação da Agropecuária no Total do Valor Adicionado o município de Araçatuba destoa dos demais sendo 2,69\% enquanto nos outros cinco essa porcentagem é menos que $1 \%$. Devido ao leque de funcionalidades que essas cidades médias possuem na rede urbana como especialidades médicas, grandes estabelecimentos comerciais como hipermercados, grandes lojas, shopping centers, cinemas, estádios de futebol, além de muitos outros tipos de serviços o setor que possui maior participação 
no valor adicionado fiscal é o de serviços nos seis municípios sendo em todos mais de $77 \%$.

Feito essas análise do ponto de vista mais econômico apresenta-se um breve perfil histórico das seis cidades médias.

\section{Araçatuba}

A cidade de Araçatuba foi fundada no ano de 1908 e teve sua origem a partir de uma estação de trem da Estrada de Ferro Noroeste do Brasil e foi "ponta de trilho" conforme denominação de Monbeig (1984). Durante a segunda metade do século XX o município se destacou pela criação de bovinos, principalmente de corte, atualmente a produção de cana de açúcar tem aumentado muito ocupando terras que antes eram utilizadas como pastagens. Foi conhecida por ser a "capital do boi gordo" em razão de a arroba do boi ser realizada em uma praça da cidade. Atualmente o setor industrial de Araçatuba é favorecido pelo Gasoduto Brasil-Bolívia.

\section{Bauru}

A cidade de Bauru foi fundada no ano de 1896 e surgiu em decorrência das estradas de ferro que tiveram seu auge no período cafeeiro do Estado de São Paulo. Bauru foi e ainda é um nó da rede ferroviária, uma vez que as principais estradas de ferro que ligam a capital ao Oeste do Estado passam pelo município como é o caso da Estrada de Ferro Noroeste do Brasil e Estrada de Ferro Sorocabana e a Companhia Paulista de Estradas de Ferro.

\section{Marília}

A cidade de Marília foi fundada no ano de 1928 (mesmo ano da chegada da ferrovia) e localiza-se a aproximadamente 400 quilômetros de sua capital e exerce influência direta sobre aproximadamente 40 municípios, sendo classificada como capital regional C pelo IBGE (2008) (MELAZZO, 2012). A cidade de Marília mantém relações regionais com os municípios do seu entorno direto, principalmente nos intensos fluxos de pessoas e mercadorias por ser centro de consumo e serviços especializados.

No caso de Marília vale registrar uma visão mais atualizada de seu papel na rede urbana e como cidade média. De acordo com Melazzo (2011, p. 165),

Geo UERJ. Rio de Janeiro - Ano 16, no. 25, v.2, $2^{\circ}$ semestre de 2014, pp.324-365 ISSN: 1415-7543 E-ISSN: 1981-9021

http://www.e-publicacoes.uerj.br/index.php/geouerj 
São marcantes as relações regionais desenvolvidas com os municípios de seu entorno direto, principalmente intensos fluxos de pessoas e serviços especializados que vem crescendo, diferenciando-se e sofisticando-se ao longo dos últimos anos, seja ainda pela presença de determinadas atividades industriais, caracterizadas pela tendência de especialização produtiva e pelas articulações produzidas em distintas escalas geográficas, cada vez mais amplas, como, por exemplo, aquelas que conferem à cidade a denominação de "capital nacional do alimento".

Esse papel exercido por Marília na rede urbana é similar ao das outras cidades médias analisadas nesse texto. Porém, apenas Marília tem a peculiaridade de se destacar nacionalmente na produção alimentícia.

\section{Presidente Prudente}

Presidente Prudente é a cidade média analisada mais distante de sua capital, está a 558 quilômetros de São Paulo. A cidade foi fundada em 1917 e pode ser considerada, conforme Monbeig "ponta de trilho", uma vez que sua localização na época de sua origem e de emancipação era próxima do final da Ferrovia Sorocabana. Presidente Prudente não foi tão beneficiada pela cultura do café, uma vez que sua fundação ocorreu em um período que a produção já enfrentava problemas com a superprodução, que causaram as conhecidas crises do café no Brasil, além disso, suas terras não eram tão férteis como de outras regiões do estado, como exemplo, as da região de Ribeirão Preto.

\section{Ribeirão Preto}

A cidade de Ribeirão Preto é a segunda mais antiga dentre as cidades analisadas, foi fundada em 1856, antes da chegada do café tipo bourbon na região em 1876 que a partir desse período permitiu um crescimento acelerado da cidade. Da mesma maneira que todas as cidades analisadas a história de Ribeirão Preto recebe influência das Estradas de Ferro, sendo beneficiada pela chegada da Companhia Mogiana de Estradas de Ferro em 1883. 


\section{São José do Rio Preto}

São José do Rio Preto é a mais antiga das seis cidades e foi fundada em 1852 e também funcionou como "ponta de trilho" por um período. A Estrada de Ferro Araraquara chegou à cidade no ano de 1912, isso deu maior impulso de crescimento à cidade e por ter sido ponta de trilho por um período tornou-se um centro de irradiação de mercadorias vindas de São Paulo e do porto de Santos para a região. É pertinente destacar que essas cidades médias nos seus processos históricos foram se tornando importantes centros comerciais e de serviços o que contribuiu para que, mesmo após o declínio da economia cafeeira no estado, essas cidades não passaram por períodos drásticos em decorrência de crises.

\section{Análise da frota de veículos em cidades médias e na capital do Estado de São Paulo}

O número de veículos no Estado de São Paulo tem aumentado de modo rápido nas últimas décadas. Numa comparação entre 1998 e 2009 é possível verificar que o número de veículos registrados no estado quase dobrou, conforme mostra a tabela 1 (para se entender os números de 1 a 7 nas linhas da tabela verificar a legenda depois da tabela). O número de veículos no Estado de São Paulo passou de 11.258.354 em 1998 para $20.258,439$ em $2009^{\mathrm{xv}}$, ou seja, houve um aumento de 44,42\% em apenas 11 anos.

Na capital São Paulo havia em janeiro de 1998 o total de 4.749 .845 veículos e em janeiro de 2010 aumentou para 6.733,100 veículos, ou seja, um acréscimo de $41,75 \%$. Esse aumento significativo sugere que o espaço urbano e suas relações com a circulação e a acessibilidade continuam no início do século XXI como um grande desafio aos que administram e atuam no ordenamento urbano. Pensar em melhorias nas condições dos deslocamentos e da acessibilidade e a produção do espaço urbano é tarefa que requererá capacidades extras dos agentes que estarão nos cargos públicos responsáveis por esse segmento. 
Tabela 1- Estado de São Paulo: Frota de veículos do Estado de São Paulo e de São Paulo - 1998-2010.

\begin{tabular}{|c|c|c|c|c|c|c|c|c|}
\hline \multicolumn{9}{|c|}{ Jan/10 } \\
\hline & 1 & 2 & 3 & 4 & 5 & 6 & 7 & Total \\
\hline Capital & 823.657 & 658.022 & 4.969 .456 & 41.810 & 164.071 & 69.917 & 6.167 & 6.733 .100 \\
\hline Estado & 3.777 .764 & 1.899 .768 & 13.298 .992 & 127.350 & 689.169 & 347.449 & 117.947 & 20.258 .439 \\
\hline \multicolumn{9}{|c|}{ Jan/08 } \\
\hline & 1 & 2 & 3 & 4 & 5 & 6 & 7 & Total \\
\hline Capital & 658.973 & 548.965 & 4.512 .118 & 40.253 & 158.865 & 64.420 & 5.640 & 5.989 .234 \\
\hline Estado & 3.061 .892 & 1.574 .530 & 11.785 .589 & 116.141 & 626.887 & 302.255 & 116.125 & 17.583 .419 \\
\hline \multicolumn{9}{|c|}{ Jan/06 } \\
\hline & 1 & 2 & 3 & 4 & 5 & 6 & 7 & Total \\
\hline Capital & 499.686 & 478.452 & 4.108 .461 & 36.493 & 148.125 & 59.293 & 5.392 & 5.335 .902 \\
\hline Estado & 2.277 .370 & 1.367 .943 & 10.553 .263 & 103.612 & 575.592 & 264.384 & 115.388 & 15.257 .552 \\
\hline \multicolumn{9}{|c|}{ Jan/04 } \\
\hline & 1 & 2 & 3 & 4 & 5 & 6 & 7 & Total \\
\hline Capital & 470.195 & 486.934 & 4.392 .056 & 41.984 & 169.453 & 75.016 & 6.433 & 5.642 .071 \\
\hline Estado & 1.993 .572 & 1.352 .595 & 10.563 .878 & 111.481 & 612.997 & 274.274 & 120.027 & 15.028 .824 \\
\hline \multicolumn{9}{|c|}{ Jan/02 } \\
\hline & 1 & 2 & 3 & 4 & 5 & 6 & 7 & Total \\
\hline Capital & 405.969 & 463.466 & 4.158 .831 & 36.577 & 167.464 & 71.893 & 6.407 & 5.310 .607 \\
\hline Estado & 1.648 .536 & 1.266 .392 & 9.782 .037 & 101.612 & 589.108 & 248.854 & 119.838 & 13.756 .377 \\
\hline \multicolumn{9}{|c|}{ Jan/00 } \\
\hline & 1 & 2 & 3 & 4 & 5 & 6 & 7 & Total \\
\hline Capital & 348.098 & 411.457 & 3.908 .816 & 36.241 & 163.421 & 67.468 & 12.638 & 4.948 .139 \\
\hline Estado & 1.383 .499 & 1.119 .380 & 8.907 .260 & 96.828 & 558.848 & 224.920 & 135.046 & 12.425 .781 \\
\hline \multicolumn{9}{|c|}{ Jan/98 } \\
\hline & 1 & 2 & 3 & 4 & 5 & 6 & 7 & Total \\
\hline Capital & 299.755 & 382.546 & 3.795 .534 & 37.836 & 162.218 & 64.604 & 7.352 & 4.749 .845 \\
\hline Estado & 1.185 .111 & 1.018 .270 & 8.109 .924 & 93.242 & 528.131 & 200.116 & 123.560 & 11.258.354 \\
\hline
\end{tabular}

Fonte: DER-SP, 2011.

Legenda:

Coluna 1: Ciclomotor, Motoneta, Motocicleta, Triciclo e Quadriciclo

Coluna 2: Micro-Ônibus, Camioneta, Caminhonete e Utilitário

Coluna 3: Automóvel

Coluna 4: Ônibus

Coluna 5: Caminhão

Coluna 6: Reboque e Semi-Reboque

Coluna 7: Outros (Caminhão Trator, Trator de Rodas, Trator de Esteiras, Trator Misto,

Chassi/Plataforma, Side-Car, Motor-Casa). 
Caso se considere as afirmações de Dawson (2006) e Sávio (2010) em relação ao fetiche do automóvel e do fato de o automóvel ser um produto "especial" para o capitalismo é possível afirmar que pensar no espaço urbano, principalmente o das cidades médias e das metrópoles, deve-se considerar as perspectivas de que esses problemas já existentes se agravarão.

Em relação às frotas municipais das cidades médias: Ribeirão Preto, São José do Rio Preto, Marília, Araçatuba, Presidente Prudente e Bauru, além do município de São Paulo com a análise das tabelas 2 e 3 é possível relacionar a evolução da frota de veículos com a da população e o crescimento em \% no período entre 2002 e 2011. Utilizar-se-á esse período que é o que possui dados disponibilizado pela Fundação Sistema Estadual de Análise de Dados (SEADE) para a frota de veículos. Na tabela 2 também há dados para o ano de 2012 da população, porém os dados da frota são disponibilizados até o ano de 2011 pela SEADE.

No município de São Paulo havia em 2002 um total de 4.213.988 veículos e em 2011 aumentou para 6.622,324, ou seja, houve um aumento de 36,36\%. Nesse mesmo período a população do município aumentou $6,17 \%$.

No município de Presidente Prudente no ano 2002 havia 69.597 veículos e em 2011 a frota aumentou para 128.001, ou seja, houve um aumento de 45,62\%. No mesmo período de 2002 a 2011 a população aumentou 7,49\%. A título de comparação, apenas de 2010 para 2011 houve um aumento de 7,10\% na frota de veículos do total do município.

O município que apresentou o maior aumento é o de Ribeirão Peto, uma vez que apresentou no período analisado um aumento de 47,33\% na sua frota de veículos passando de 224.190 veículos em 2002 para 425.690 em 2011, porém no mesmo período a população aumentou 14,31\%, passou de 524.714 em 2002 para 621.038 em 2011.

O município da tabela 2 que apresentou a menor taxa de crescimento da frota de veículos, com exceção de São Paulo, é Bauru (43,78\%), porém não foi o que apresentou a menor taxa de crescimento populacional $(6,96 \%)$. A menor taxa de crescimento 
populacional foi no município de Araçatuba (6,28\%), mas a da frota de veículos nesse município aumentou 45,12\% entre 2002 e 2011.

Tabela 2- Estado de São Paulo: Frota total de veículos em cidades médias e em São Paulo 2002-2011.

\begin{tabular}{|c|c|c|c|c|c|c|c|c|c|c|c|}
\hline $\mathbf{M u}$ & 2002 & 2003 & 2004 & 2005 & 2006 & 2007 & 2008 & 2009 & 2010 & 2011 & $\begin{array}{l}\text { Cresciment } \\
\text { o entre } \\
2002 \text { e } 2011 \\
(\text { em \%) }\end{array}$ \\
\hline Araç & $\begin{array}{c}72.5 \\
13\end{array}$ & $\begin{array}{c}76.6 \\
06\end{array}$ & $\begin{array}{c}81.3 \\
24\end{array}$ & $\begin{array}{c}85.3 \\
68\end{array}$ & $\begin{array}{c}91.2 \\
23\end{array}$ & $\begin{array}{c}98.5 \\
87\end{array}$ & $\begin{array}{l}106 . \\
734\end{array}$ & $\begin{array}{l}114 . \\
586\end{array}$ & $\begin{array}{l}123 . \\
041\end{array}$ & $\begin{array}{l}132 . \\
141\end{array}$ & $45,12 \%$ \\
\hline Bauru & $\begin{array}{l}122 . \\
305\end{array}$ & $\begin{array}{l}125 . \\
450\end{array}$ & $\begin{array}{l}129 . \\
969\end{array}$ & $\begin{array}{l}137 . \\
054\end{array}$ & $\begin{array}{l}147 . \\
924\end{array}$ & $\begin{array}{l}161 . \\
275\end{array}$ & $\begin{array}{l}174 . \\
728\end{array}$ & $\begin{array}{l}188 . \\
069\end{array}$ & $\begin{array}{c}203 . \\
651\end{array}$ & $\begin{array}{l}217 . \\
548\end{array}$ & $43,78 \%$ \\
\hline M & $\begin{array}{c}68.1 \\
42\end{array}$ & $\begin{array}{c}70.9 \\
78\end{array}$ & $\begin{array}{c}74.6 \\
45\end{array}$ & $\begin{array}{c}78.3 \\
76\end{array}$ & $\begin{array}{c}83.1 \\
42\end{array}$ & $\begin{array}{c}89.3 \\
14\end{array}$ & $\begin{array}{c}96.8 \\
54\end{array}$ & $\begin{array}{l}105 . \\
228\end{array}$ & $\begin{array}{l}113 . \\
428\end{array}$ & $\begin{array}{l}122 . \\
453\end{array}$ & 44, \\
\hline $\begin{array}{c}\text { Presidente } \\
\text { Prudente }\end{array}$ & $\begin{array}{c}69.5 \\
97\end{array}$ & $\begin{array}{c}72.1 \\
75\end{array}$ & $\begin{array}{c}76.7 \\
30\end{array}$ & $\begin{array}{c}81.4 \\
60\end{array}$ & $\begin{array}{c}86.5 \\
46\end{array}$ & $\begin{array}{c}93.1 \\
66\end{array}$ & $\begin{array}{l}101 . \\
186\end{array}$ & $\begin{array}{l}109 . \\
176\end{array}$ & $\begin{array}{l}118 . \\
905\end{array}$ & $\begin{array}{l}128 . \\
001\end{array}$ & $45,62 \%$ \\
\hline $\begin{array}{c}\text { Ribeirão } \\
\text { Preto }\end{array}$ & $\begin{array}{c}224 . \\
190 \\
\end{array}$ & $\begin{array}{l}235 . \\
338 \\
\end{array}$ & $\begin{array}{l}247 . \\
758 \\
\end{array}$ & $\begin{array}{l}262 . \\
813 \\
\end{array}$ & $\begin{array}{l}281 . \\
469 \\
\end{array}$ & $\begin{array}{l}307 . \\
080 \\
\end{array}$ & $\begin{array}{l}335 . \\
364\end{array}$ & $\begin{array}{l}363 . \\
778\end{array}$ & $\begin{array}{l}397 . \\
919 \\
\end{array}$ & $\begin{array}{r}425 . \\
690 \\
\end{array}$ & $47,33 \%$ \\
\hline $\begin{array}{c}\text { São José } \\
\text { do Rio } \\
\text { Preto }\end{array}$ & $\begin{array}{l}162 . \\
445\end{array}$ & $\begin{array}{l}169 . \\
747\end{array}$ & $\begin{array}{l}179 . \\
515\end{array}$ & $\begin{array}{l}191 . \\
404\end{array}$ & $\begin{array}{c}206 . \\
101\end{array}$ & $\begin{array}{l}224 . \\
248\end{array}$ & $\begin{array}{l}244 . \\
007\end{array}$ & $\begin{array}{l}262 . \\
321\end{array}$ & $\begin{array}{l}283 . \\
099\end{array}$ & $\begin{array}{l}303 . \\
444\end{array}$ & $46,46 \%$ \\
\hline $\mathbf{S a ̃}$ & \begin{tabular}{|c}
4.21 \\
3.98 \\
8
\end{tabular} & $\begin{array}{c}4.38 \\
2.90 \\
7\end{array}$ & $\begin{array}{c}4.54 \\
7.84 \\
2\end{array}$ & $\begin{array}{c}4.75 \\
2.09 \\
2\end{array}$ & $\begin{array}{c}5.03 \\
7.41 \\
8\end{array}$ & $\begin{array}{c}5.39 \\
2.69 \\
2\end{array}$ & $\begin{array}{c}5.80 \\
4.56 \\
6\end{array}$ & $\begin{array}{c}6.14 \\
0.18 \\
9\end{array}$ & $\begin{array}{c}6.39 \\
0.09 \\
2\end{array}$ & $\begin{array}{c}6.62 \\
2.32 \\
4\end{array}$ & $36,36 \%$ \\
\hline
\end{tabular}

Fonte: SEADE, 2012.

Tabela 3 - Estado de São Paulo: População total em cidades médias e em São Paulo 2002-2011.

\begin{tabular}{|c|c|c|c|c|c|c|c|c|c|c|c|c|}
\hline $\begin{array}{c}\text { Municí } \\
\text { pio }\end{array}$ & 2002 & 2003 & 2004 & 2005 & 2006 & 2007 & 2008 & 2009 & 2010 & 2011 & 2012 & $\begin{array}{c}\text { Cresci } \\
\text { mento } \\
\text { entre } \\
2002 \text { e } \\
2011 \\
(\mathrm{em} \\
\%)\end{array}$ \\
\hline $\begin{array}{c}\text { Araçatu } \\
\text { ba }\end{array}$ & $\begin{array}{c}172.0 \\
10\end{array}$ & $\begin{array}{l}173 . \\
289\end{array}$ & $\begin{array}{l}174 . \\
526\end{array}$ & $\begin{array}{l}175 . \\
829\end{array}$ & $\begin{array}{l}177 . \\
016\end{array}$ & $\begin{array}{l}178 . \\
059\end{array}$ & $\begin{array}{l}179 . \\
186\end{array}$ & $\begin{array}{l}180 . \\
316\end{array}$ & $\begin{array}{l}181 . \\
473\end{array}$ & $\begin{array}{l}182 . \\
474\end{array}$ & $\begin{array}{l}183 . \\
480\end{array}$ & $6,28 \%$ \\
\hline Bauru & $\begin{array}{c}321.8 \\
11\end{array}$ & $\begin{array}{l}324 . \\
715\end{array}$ & $\begin{array}{l}327 . \\
726\end{array}$ & $\begin{array}{l}330 . \\
750\end{array}$ & $\begin{array}{l}333 . \\
526\end{array}$ & $\begin{array}{l}336 . \\
085\end{array}$ & $\begin{array}{c}338 . \\
648\end{array}$ & $\begin{array}{l}341 . \\
125\end{array}$ & $\begin{array}{l}343 . \\
695\end{array}$ & $\begin{array}{l}345 . \\
913\end{array}$ & $\begin{array}{l}348 . \\
145\end{array}$ & $6,96 \%$ \\
\hline Marília & $\begin{array}{c}201.4 \\
01\end{array}$ & $\begin{array}{l}203 . \\
497\end{array}$ & $\begin{array}{l}205 . \\
464\end{array}$ & $\begin{array}{l}207 . \\
429 \\
\end{array}$ & $\begin{array}{l}209 . \\
355\end{array}$ & $\begin{array}{l}211 . \\
119\end{array}$ & $\begin{array}{l}212 . \\
849\end{array}$ & $\begin{array}{c}214 . \\
638 \\
\end{array}$ & $\begin{array}{l}216 . \\
576\end{array}$ & $\begin{array}{l}218 . \\
165\end{array}$ & $\begin{array}{l}219 . \\
765\end{array}$ & $7,68 \%$ \\
\hline Preside & 193.2 & 195. & 196. & 198. & 200. & 202. & 204. & 205. & 207. & 208. & 210. & $7,49 \%$ \\
\hline
\end{tabular}




\begin{tabular}{|c|c|c|c|c|c|c|c|c|c|c|c|c|}
\hline $\begin{array}{c}\text { nte } \\
\text { Prudent } \\
\text { e }\end{array}$ & 35 & 132 & 965 & 813 & 688 & 480 & 165 & 783 & 449 & 900 & 361 & \\
\hline $\begin{array}{l}\text { Ribeirã } \\
\text { o Preto }\end{array}$ & $\begin{array}{c}524.7 \\
14\end{array}$ & $\begin{array}{l}534 . \\
828\end{array}$ & $\begin{array}{l}544 . \\
897\end{array}$ & $\begin{array}{l}554 . \\
996\end{array}$ & $\begin{array}{l}564 . \\
808\end{array}$ & $\begin{array}{l}574 . \\
315\end{array}$ & $\begin{array}{l}583 . \\
910\end{array}$ & $\begin{array}{l}593 . \\
710\end{array}$ & $\begin{array}{l}603 . \\
774\end{array}$ & $\begin{array}{l}612 . \\
346\end{array}$ & $\begin{array}{l}621 . \\
038\end{array}$ & $\begin{array}{c}14,31 \\
\%\end{array}$ \\
\hline $\begin{array}{c}\text { São } \\
\text { José do } \\
\text { Rio } \\
\text { Preto }\end{array}$ & $\begin{array}{c}368.2 \\
40\end{array}$ & $\begin{array}{l}373 . \\
298\end{array}$ & $\begin{array}{l}378 . \\
289\end{array}$ & $\begin{array}{c}383 . \\
181\end{array}$ & $\begin{array}{l}387 . \\
956\end{array}$ & $\begin{array}{l}392 . \\
682\end{array}$ & $\begin{array}{l}397 . \\
490\end{array}$ & $\begin{array}{l}402 . \\
475\end{array}$ & $\begin{array}{l}407 . \\
816\end{array}$ & $\begin{array}{l}412 . \\
219\end{array}$ & $\begin{array}{l}416 . \\
670\end{array}$ & $\begin{array}{c}10,66 \\
\%\end{array}$ \\
\hline $\begin{array}{c}\text { São } \\
\text { Paulo }\end{array}$ & $\begin{array}{l}10.61 \\
3.691\end{array}$ & $\begin{array}{c}10.6 \\
98.3 \\
81\end{array}$ & $\begin{array}{c}10.7 \\
82.2 \\
96\end{array}$ & $\begin{array}{c}10.8 \\
65.5 \\
73\end{array}$ & $\begin{array}{c}10.9 \\
44.8 \\
89\end{array}$ & $\begin{array}{c}11.0 \\
19.4 \\
84\end{array}$ & $\begin{array}{c}11.0 \\
93.7 \\
46\end{array}$ & $\begin{array}{c}11.1 \\
68.1 \\
94\end{array}$ & $\begin{array}{c}11.2 \\
45.9 \\
83\end{array}$ & $\begin{array}{c}11.3 \\
12.3 \\
51\end{array}$ & $\begin{array}{c}11.3 \\
79.1 \\
14\end{array}$ & $6,17 \%$ \\
\hline
\end{tabular}

Fonte: SEADE, 2012.

Tabela 4 - Estado de São Paulo: número de habitantes por total de veículos em cidades médias e na capital $2002-2011$.

\begin{tabular}{c|r|r|r|r|r|r|r|r|r|r}
\hline Município & $\mathbf{2 0 0 2}$ & $\mathbf{2 0 0 3}$ & $\mathbf{2 0 0 4}$ & $\mathbf{2 0 0 5}$ & $\mathbf{2 0 0 6}$ & $\mathbf{2 0 0 7}$ & $\mathbf{2 0 0 8}$ & $\mathbf{2 0 0 9}$ & $\mathbf{2 0 1 0}$ & $\mathbf{2 0 1 1}$ \\
\hline Araçatuba & 2,52 & 2,44 & 2,37 & 2,29 & 2,17 & 2,04 & 1,91 & 1,82 & 1,76 & 1,71 \\
\hline Bauru & 2,34 & 2,27 & 2,2 & 2,11 & 2,01 & 1,87 & 1,74 & 1,63 & 1,52 & 1,44 \\
\hline Marília & 2,63 & 2,59 & 2,52 & 2,41 & 2,25 & 2,08 & 1,94 & 1,81 & 1,69 & 1,59 \\
\hline Presidente Prudente & 2,27 & 2,2 & 2,11 & 2 & 1,88 & 1,75 & 1,63 & 1,53 & 1,44 & 1,36 \\
\hline Ribeirão Preto & 2,37 & 2,26 & 2,15 & 2,06 & 1,94 & 1,81 & 1,68 & 1,57 & 1,47 & 1,38 \\
\hline São José do Rio Preto & 2,78 & 2,7 & 2,57 & 2,44 & 2,32 & 2,17 & 2,02 & 1,88 & 1,74 & 1,63 \\
\hline São Paulo & 2,96 & 2,87 & 2,75 & 2,65 & 2,52 & 2,36 & 2,2 & 2,04 & 1,91 & 1,78 \\
\hline
\end{tabular}

Fonte: SEADE, 2012.

A tabela 4 mostra a relação entre o número de habitantes pelo total de veículos no período entre 2002 e 2011. A análise da tabela 4 revela que até o ano de 2002 havia mais de dois habitantes por veículo em todas as cidades, apenas em 2005 em Presidente Prudente essa relação já era de dois habitantes por veículos. Após o ano de 2010 em todas as cidades essa relação passou a ser de menos de dois, sendo Presidente Prudente a menor proporção são 1,36 habitante por veículo em 2011. Todas as cidades médias tinham proporção menor do que São Paulo em 2011, que também tem uma proporção baixa de habitantes por veículo 1,78 .

Se se considerar que um carro popular ocupa nas vias públicas em média um espaço de quatro metros quadrados é possível afirmar que é necessário em torno de 13.244,648 metros quadrados de vias públicas e estacionamentos se a metade dos 
veículos da cidade de São Paulo estivesse circulando em um mesmo dia em 2011. Assim, se torna "natural" quando se ouve moradores de cidades como São José do Rio Preto, Presidente Prudente e Ribeirão Preto, por exemplo, reclamarem que o trânsito de suas respectivas cidades está causando transtornos, estresse, acidentes, demora, falta de estacionamentos nas vias e espaços públicos. É comum na área central de São José do Rio Preto encontrar três ou quatro estacionamentos privados em um único quarteirão ${ }^{\mathrm{xvi}}$.

Para trazer um exemplo empírico da relação entre os meios de transporte e as vias de transporte nas cidades médias tomar-se-á como fato recente um alargamento de acesso a uma Avenida na cidade de São José do Rio Preto. Trata-se da Avenida Alberto Andaló, umas das principais da cidade, nela se localiza diversos estabelecimentos comerciais, bares, churrascarias, restaurantes e também a prefeitura da cidade, nessa avenida há diariamente problemas com o trânsito. Na sequencia dessa avenida está a Avenida José Munia onde estão localizados empreendimentos de grande porte como o hipermercado Walmart e o Plaza Avenida Shopping. Esses dois grandes empreendimentos estão localizados a menos de 300 metros do cruzamento com a rodovia Washington Luis (SP 310) que corta o perímetro urbano da cidade, o cruzamento entre a avenida e a rodovia é por meio de viaduto, porém há lentidão no trânsito nas imediações nos horários de pico. Assim, alguns motoristas que circulam no espaço urbano acessam a rodovia com objetivo de "fugir" dos congestionamentos das principais avenidas. Para buscar soluções, o poder público está realizando obras retirando parte do barranco ao lado da rodovia SP 310 para facilitar o acesso à Avenida Alberto Andaló, conforme mostra a foto 1.

De acordo com Pereira (2012),

Por conta de um semáforo, o acesso que leva à Avenida Andaló e à Marginal começou a formar filas que avançavam pela rodovia, causando acidentes e desconforto. A solução encontrada foi prolongar o acesso em mais 100 metros, removendo parte da terra que margeava a estrada. $\mathrm{O}$ alívio vai durar pouco. A solução vai dar em nada. Logo, logo, o aumento da frota vai esgotar o espaço de 180 metros. Uma hora, o barranco lateral acaba. E os carros voltam a se acumular perigosamente na rodovia. Isso está acontecendo em dezenas de cidades brasileiras de porte médio. Há um enorme aumento das 
frotas de carros e motos e essas cidades não foram dimensionadas para isso. Geralmente têm um centro velho com vias estreitas, onde quase todo comércio se concentra (PEREIRA, 2012, não paginado).

Foto 1: São José do Rio Preto: obras nas margens da rodovia Washington Luis (SP 310) no acesso à avenida Alberto Andaló, 2012.

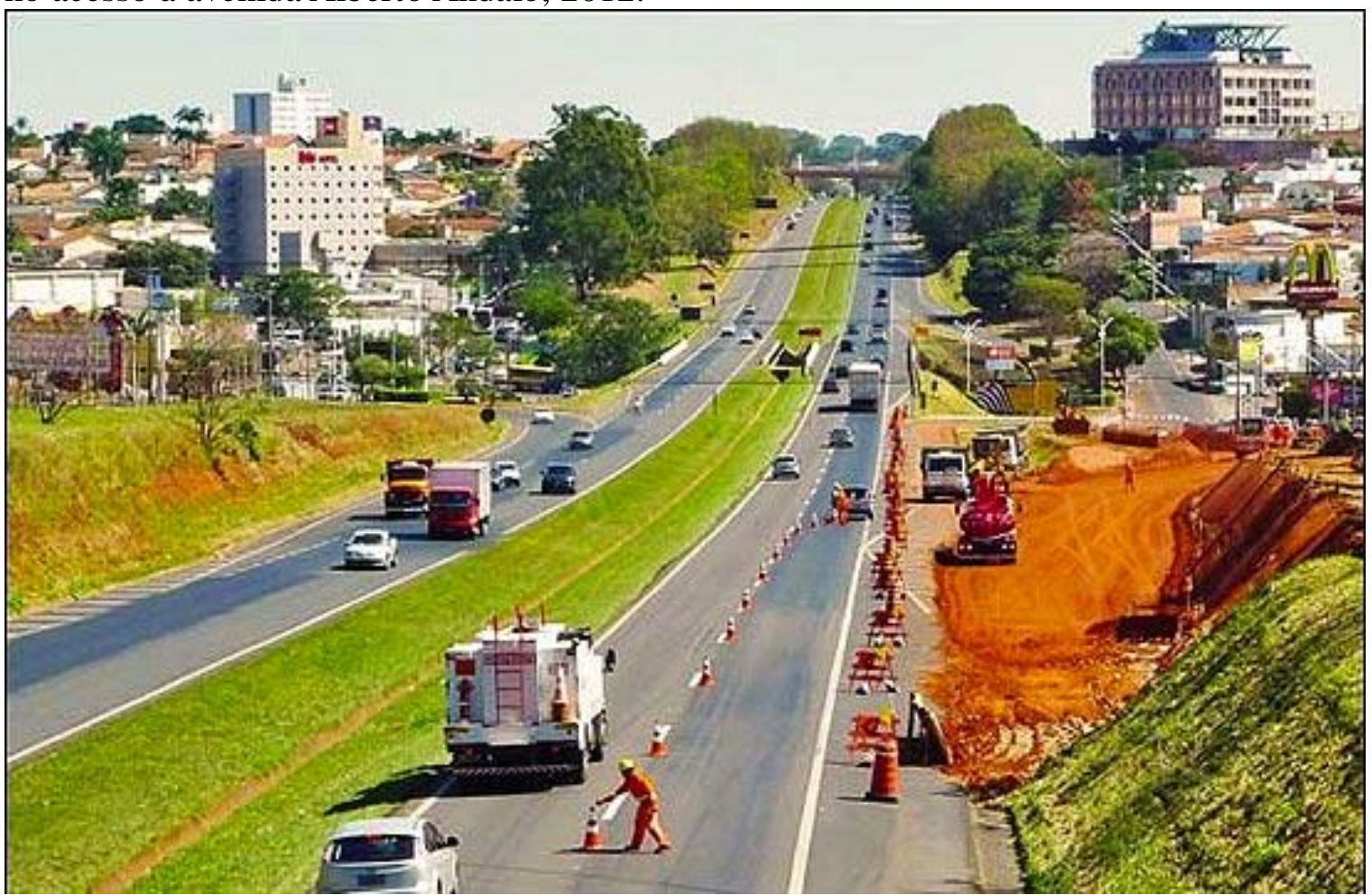

Fonte: Toninho Cury, divulgação, 2012.

Foto 2: São José do Rio Preto: obra de acesso à avenida Alberto Andaló concluída, 2012. 


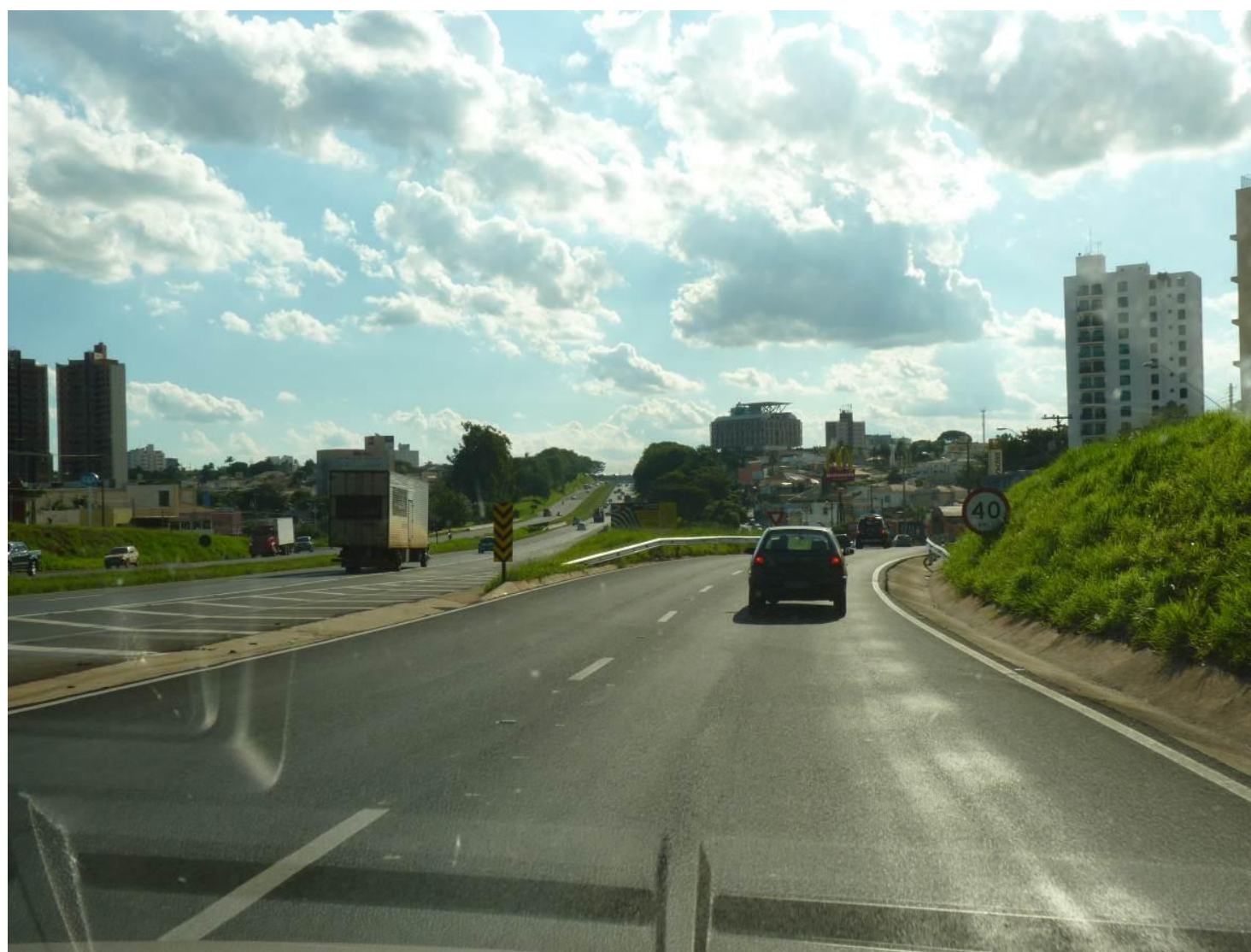

Fonte: tirada pelo autor, 2013.

Problemas como esse, destacado por Pereira (2012), em São José do Rio Preto também acontecem na Avenida Bady Bassit que possui o mesmo sentido que a Avenida Alberto Andaló e também cruza com a rodovia Washington Luis, conforme mostra a figura 1. Nesta Avenida também se localiza muitos estabelecimentos comerciais com destaque para concessionárias de veículos e de motocicletas, além de estabelecimentos de diversos tipos que geram demandas de acessibilidade diária significativa. 


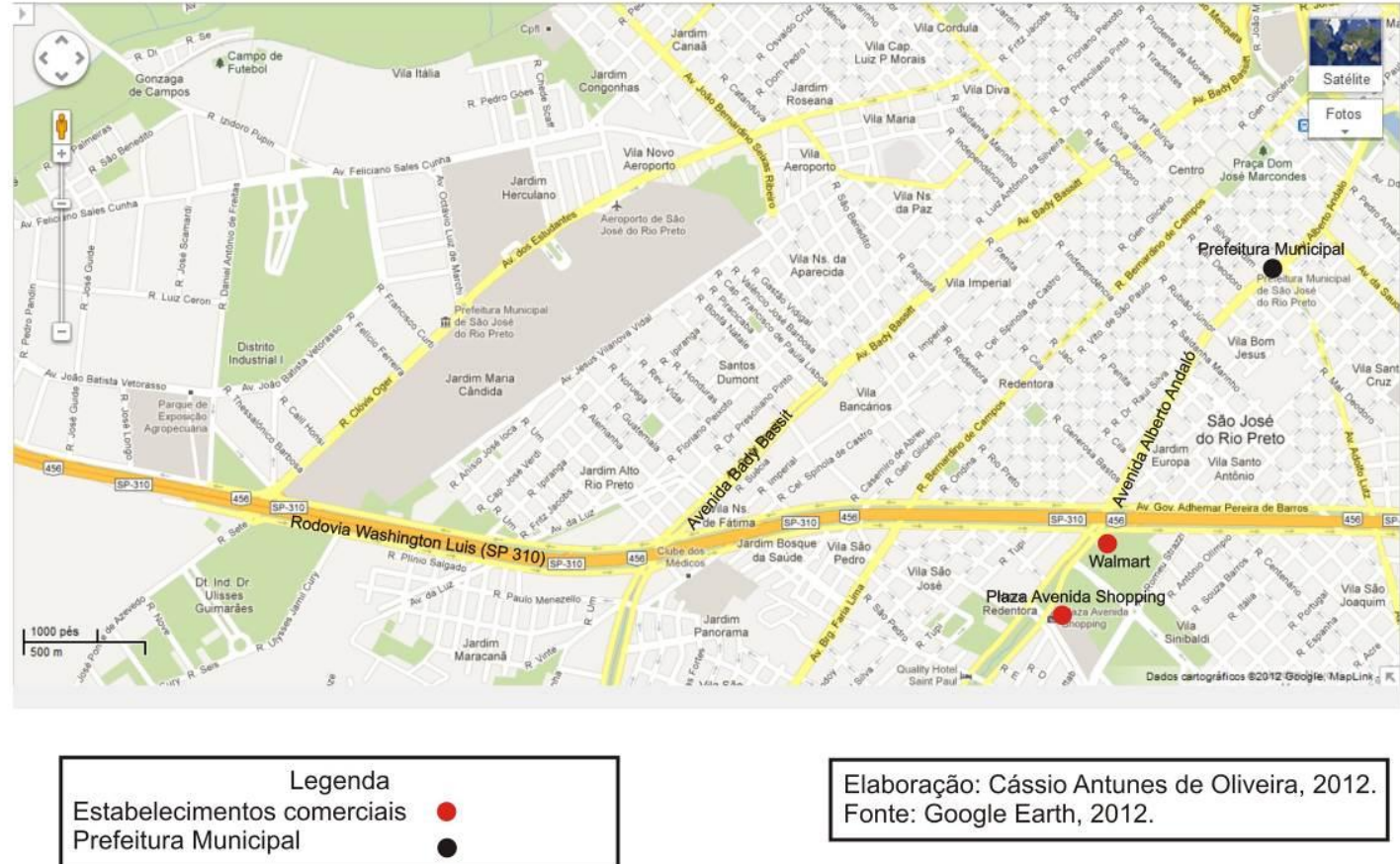

Figura 1: São José do Rio Preto (SP): localização das Avenidas Alberto Andáló e Bady Bassit e da rodovia Washington Luis (SP 310).

A área central de São José do Rio Preto se localiza entre as Avenidas Alberto Andaló e Bady Bassit. Nessa área estão a maioria dos consultórios médicos, dentistas, laboratórios, hospitais, shoppings, concessionárias de veículos e diversos estabelecimentos de comércio de varejo. Se considerar que essas cidades médias analisadas funcionam como centros regionais é necessário considerar, além dos fluxos gerados pela frota de veículo municipal, também os veículos de outros municípios que se dirigem a essas cidades diariamente, inclusive nos finais de semana e feriados em busca de lazer e de compras, principalmente em shoppings centers.

\section{Considerações finais}

As cidades brasileiras apresentam diferenças em relação às europeias em razão de dois fatores um histórico e outro socioeconômico. O histórico está relacionado ao período de formação das cidades, que no caso do Brasil é mais recente. Há muitas 
cidades brasileiras que ainda não completaram um século de existência, como exemplos, Londrina e Maringá no Paraná e Presidente Prudente no Estado de São Paulo. Assim, a produção do espaço urbano dessas cidades ocorreu em um período histórico mais curto. O outro fator, o socioeconômico está relacionado ao fato de no Brasil existir mais desigualdades sociais que nos países europeus, isto reflete na materialização das cidades. Desta forma, ao se fazer releituras de conceitos elaborados por autores europeus que tomaram como recorte empírico a realidade de cidades europeias é necessário ter cautela ao se relacionar tais análises com a realidade brasileira.

Em relação ao relacionamento entre a acessibilidade e o crescimento das frotas de veículos das cidades brasileiras e articular com problemas que surgem nas cidades brasileiras é possível perceber essas diferenças entre as realidades brasileira e europeia. No Caso do conceito de cidade difusa ocorre o mesmo. No Brasil ainda não há uma cidade que seja propriamente difusa nos termos de Indovina (2004), uma vez que todas ainda possuem áreas concentradas. Mas é possível verificar tendências como as identificadas na Região Metropolitana de Campinas.

As cidades brasileiras principalmente as grandes e médias no que se refere às condições de acessibilidade, mobilidade, deslocamentos terão, como desafio de gestão, que lidar com o aumento das frotas de veículos que causam problemas diários como o exemplo de São José do Rio Preto. Assim, a desconcentração de atividades dos centros que mais possuem demanda de acessibilidade e a melhoria do transporte coletivo deve ser um das principais enfoques dos poderes públicos municipais. A tendência de formação de cidade difusa, conforme na Itália, significa uma saída espontânea a esses tipos de problemas, uma vez que é possível a existência de "cidades sem centro", pois não há uma concentração de atividades que atraem número significativo de pessoas diariamente em uma área específica do espaço urbano. Porém, em países como o Brasil em que há expressiva desigualdade econômica as possibilidades de continuação de cidades com áreas muito concentradas permanece.

Esse texto teve como objetivo refletir sobre conceitos e noções relacionados à produção do espaço urbano e trazer à tona problemas que estão surgindo e que requerem soluções rápidas. 


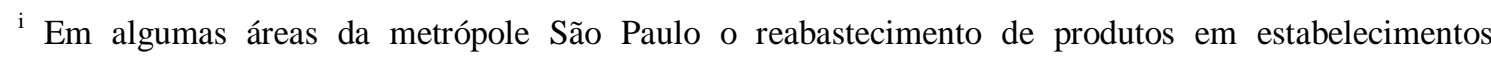
comerciais só é feito no período noturno, uma vez que sua realização no horário comercial afetaria gravemente o trânsito nas referidas áreas.

ii "A história desse importante artefato técnico tem o seu início, muito provavelmente, no século XVII, quando um capitão do exército francês, Nicolas Joseph Cugnot (Encyclopedia Britannica, 2:514), construiu um veículo de autopropulsão de três rodas, movido a vapor. [...] o primeiro automóvel com motor de combustão interna foi patenteado em 1860 pelo francês Jean Joseph Lenoir. Seu motor com apenas um cilindro e movido à gasolina, atingia a velocidade máxima de $6,4 \mathrm{~km} / \mathrm{h}$. Pouco tempo depois o construtor austríaco Siegrfield Marcus produziu uma carruagem movida à gasolina [...]. apesar de seu desenvolvimento ter ocorrido simultaneamente em diversos países, aquilo que hoje concebemos como sendo os primeiros modelos do motor a explosão tem sua origem na Alemanha, onde o trabalho pioneiro para a produção de uma máquina que fosse menor e pudesse servir como propulsor para carros teve o seu primeiro impulso. Os principais nomes ligados a esse desenvolvimento foram Nikolaus August Otto, Gottlieb Daimler e Karl Benz" (SÁVIO, 2012, p. 194).

iii Arquivos de aula.

iv Há outras áreas da ciência que também utilizam a noção de acessibilidade como é o caso de Vasconcellos (1996) que compreende acessibilidade de uma forma mais específica, sendo muito mais relacionada aos deslocamentos. Para Vasconcellos (1996, p 14) "a acessibilidade, vista como a facilidade de atingir os destinos desejados, é a medida mais direta (positiva) dos efeitos de um sistema de transporte".

${ }^{v}$ Nesse exemplo parte-se de um modelo de cidade em que as principais atividades econômicas e de serviços estão localizadas no centro, porém sabe-se que atualmente existem cidades policêntricas.

vi “A inadequação da aplicação do termo se quisermos tratá-lo como um conceito é, entretanto, notada quando o utilizamos para fazer referência a todo o anel que compreende o entorno urbano, quando, de fato, áreas sem uso, áreas industriais e áreas residenciais de alto e médio padrão também podem ser encontradas nessa área" [...] (SPOSITO, 2004, p. 284-285).

vii [...] "la vida social se há amoldado al marco urbano y parece difícil prescindir de él, incluso hoy en que las nuevas tecnologias permiten imaginar un poblamiento disperso conectado instantáneamente com todo el mundo a través del telefono y la red electrónica mundial" (CAPEL, 2002, p. 14).

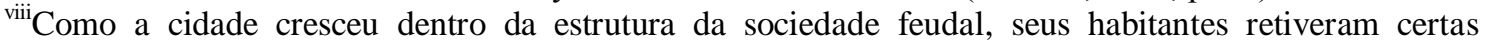
relações de dependência quanto a um senhor, e a qualificação para cidadania continuou sendo essencialmente agrícola - a propriedade de terra dentro de fronteiras; só mais tarde é que o comércio se tornou uma ocupação principal dos habitantes. A única linha divisória que podemos traçar, ao que se afirma, entre a aldeia inicial e a cidade mais tarde, está na fortificação do lugar numa certa data, quando se erigia um muro para a proteção de seus habitantes, convertendo-a assim num oppidum (DOBB, 1973, p. 98). Para Capel (2002) "las ciudades han tenido murallas desde las primeras civilizaciones hasta el siglo XIX. Una permanencia tan larga refleja, sin duda, las funciones importantes atribuídas a esas defensas, y há devido de tener consecuencias importantes sobre el desarollo urbano" (p. 125). E para Sposito (1991) "As cidades eram cercadas por muros e algumas tinham fossos, o que individualizava de forma clara o espaço urbano, e facilitava a tarefa dos governantes de defender seus governados de um ataque inimigo" ( p. 20).

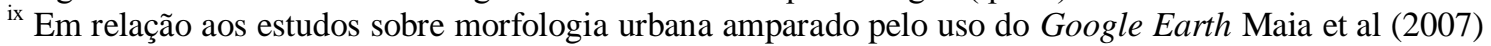
afirmam que "el estudio de la morfología urbana ofrece diversas dimensiones. En especial, es posible poner énfasis en la trama urbana y el plano (calles, manzanas, parcelario), en los usos del suelo y en los edifícios" ( sem paginação).

${ }^{x}$ Os loteamentos para construção de segunda moradia geralmente ocupam terrenos maiores e exploram áreas verdes próximas e áreas para lazer e jardins dentro dos lotes.

${ }^{x i}$ Sposito (2004) denomina essas áreas como difusão reticular ao invés de cidade difusa. Para a autora "A identificação de uma difusão urbana do tipo reticular no Estado de São Paulo está associada ao movimento de concentração e desconcentração espacial da metrópole paulista para o interior, nos últimos trinta anos" [...] (SPOSITO, 2004, p. 175).

xii Disponível em: < http://www.dicio.com.br/fetiche/>. Acesso em: 02 dez. 2012.

xiii "Com ele e a elite paulista, o automóvel virou algo mais do que um meio alternativo de transporte, se transformando num paradigma de ser paulista' (SÁVIO, 2010 apud. HAAG, 2011, p. 83). A mentalidade geral desses homens defendia a superação do 'atraso' nacional e estadual com a construção de estradas

Geo UERJ. Rio de Janeiro - Ano 16, no. 25, v.2, $2^{\text {o }}$ semestre de 2014, pp.324-365

ISSN: 1415-7543 E-ISSN: 1981-9021

http://www.e-publicacoes.uerj.br/index.php/geouerj 
que possibilitassem uma ligação rápida do interior com a capital, de forma que todo o poder e a riqueza da civilização paulista pudessem influenciar a transformação do interior do Brasil" (HAAG, 2011, p. 83).

xiv Alguns modelos da marca italiana Ferrari atingiram este valor em 2008, de acordo com a revista Carro, edição de março de 2008.

${ }^{x v}$ No ano de 1903 havia 16 veículos registrados na cidade de São Paulo (SÁVIO, 2010, p. 198). Essa informação confirma que em São Paulo e no Brasil o automóvel no início do século ainda não era um objeto difundido nas cidades. Essa difusão só ocorreu de fato a partir do início da segunda metade do século XX.

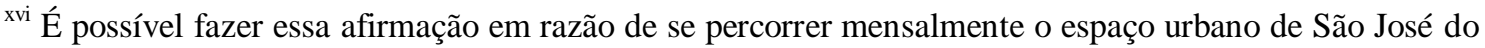
Rio Preto, principalmente a área central.

\section{REFERÊNCIAS}

ANFAVEA. Associação Nacional dos Fabricantes de Veículos Automotores. Anuário da indústria automobilística brasileira. São Paulo: Published By, 2010.

BARAT, Josef. A evolução dos transportes no Brasil. Rio de Janeiro: IBGE: IPEA, 1978.

BELlET, Carmen; ALONSO, Pilar; CASELlAS, Antònia. Infraestructuras de transporte y território. Los efectos estructurantes de la llegada del tren de alta velocidade en España. Boletín de la Asociación de Geógrafos Españoles. N. 52, pp. 143-163. 2007.

BOTELHO, Adriano. O urbano em fragmentos. A produção do espaço e da moradia pelas práticas do setor imobiliário. São Paulo: Annablume; FAPESP, 2007.

BRANCO, Maria Luisa Gomes Castello. Algumas considerações sobre a identificação de cidades médias. In. SPOSITO, Maria Encarnação Beltrão (org.). Cidades médias: espaços em transição. São Paulo: Expressão Popular, 2007.

BRANDÃO, Antonio Carlos. Território e desenvolvimento. As múltiplas escalas entre o local e o global. Campinas: Editora da Unicamp, 2007.

CAIADO, Maria Célia Silva; PIRES, Maria Conceição Silvério. Expansão recente na região metropolitana de Campinas: dispersão e novas formas urbanas. In. REIS, Nestor Goulart; TANAKA, Marta Soban (org). Brasil: Estudos sobre dispersão urbana. São Paulo: FAU - USP, 2007.

CAMAGNI, Roberto. Economía urbana. Barcelona: Antoni Bosch Editor, 2005.

CAPEL, Horacio. La morfología da las ciudades: sociedade, cultura y paisage urbano. Barcelona: Ediciones del Serbal, 2002a.

CARLOS, Ana Fani Alessandri. Diferenciação socioespacial. Revista Cidades. Presidente Prudente. N. 6, v. 4, jan. dez. p. 46-60, 2007.

CORRÊA, Roberto Lobato. Diferenciação sócio-espacial, escala e práticas espaciais. Revista Cidades. Presidente Prudente. N. 6, v. 4, jan. dez. p. 61-72, 2007.

DAWSON, Michael. O desperdício capitalista nos transportes. [2006]. Online 2012. Disponível em: <http://resistir.info/energia/automovel.html>. Acesso em: 28 nov. 2012. 
DEMATTEIS, Giuseppe. Suburbanización y periurbanización. Ciudades anglosajonas y ciudades latinas. In: MONCLÚS, Francisco J. (Ed.). La ciudad dispersa. Barcelona: Centro de Cultura Contemporánea de Barcelona, 1998.

DOBB, Maurice. A evolução do capitalismo. Rio de Janeiro: Jorge Zahar, 1973.

FARRET, Ricardo L. paradigmas da estruturação do espaço residencial intra-urbano. In: O espaço da cidade. contribuições à análise urbana. González, Suely Franco Netto et al. (orgs). São Paulo: Projeto, 1985. pp. 73-90.

HAAG, Carlos. Fé na modernidade e pé na tábua: a polêmica relação que o Brasil criou com o automóvel. In. Revista Pesquisa FAPESP. São Paulo. n. 179, p. 81-85, jan. 2011.

HARVEY, David. A condição pós-moderna: uma pesquisa sobre as origens da mudança cultural. São Paulo: Edições Loyola, 2003.

INDOVINA, Francesco. La ciudad difusa. In. RAMOS, A. R. (Ed). Lo urbano en 20 autores contemporáneos. Barcelona: Ediciones UPC, 2004.

JIMENEZ, Sara G. El enfoque neoclasico de la organización espacial y El mercado de suelo. Lincoln Instituto f land policy. 2006, 5 pp. Mimeografado.

LEFÈBVRE, Henri. O pensamento marxista e a cidade. Lisboa: Ulisseia, 1972.

MELAZZO, Everaldo Santos. Marília: especialização industrial e diversificação do consumo. Trajetórias de uma cidade média. In. SPOSITO, Maria Encarnação Beltrão; ELIAS, Denise; SOARES, Beatriz Ribeiro (Org.). Agentes econômicos e reestruturação urbana regional: Chillán e Marília. São Paulo: Outras Expressões, 2012.

MONBEIG, Pierre. Pioneiros e fazendeiros de São Paulo. São Paulo: Hucitec, 1984.

PEREIRA, Jorge Luiz Portella. A mobilidade nas cidades médias. Disponível em: <http://www1.folha.uol.com.br/colunas/joseluizportella/1170992-a-mobilidade-nascidades-medias.shtml>. Acesso em: 29 nov. 2012.

REINOSO, Alexis Sancho; et al. El uso de Google Earth para el estúdio de la morfologia de las ciudades, alcances y limitaciones. Ar@cne. Revista electrónica de recursos en Internet sobre Geografía y Ciencias Sociales. Barcelona: Universidad de Barcelona, $\mathrm{n}^{\mathrm{o}}$ 100, 1 de setembro de 2007. Disponível em: < http://www.ub.edu/geocrit/aracne/aracne-100.htm>. Acesso em: 15 dez. 2012.

SÁVIO, Marco A. A cidade e as máquinas: bondes e automóveis nos primórdios da metrópole 1900-1930. São Paulo: Annablume, 2010.

SECCHI, Bernardo. A cidade contemporânea e seu projeto. In: REIS, Nestor Goulart. Dispersão urbana: diálogo sobre pesquisas Brasil - Europa. São Paulo: FAU - USP, 2007.

SPOSITO, Maria Encarnação Beltrão. Capitalismo e urbanização. São Paulo: Contexto, 1991. 3. Ed.

SPOSITO, Maria Encarnação Beltrão. O chão em pedaços: urbanização, economia e cidades no Estado de São Paulo, 2004. Tese (Livre Docência) - Faculdade de Ciências e Tecnologia, Universidade Estadual Paulista, Presidente Prudente. 
SPOSITO, Maria Encarnação Beltrão; ELIAS, Denise; SOARES, Beatriz Ribeiro; MAIA, Doralice Sátyro; GOMES, Edvânia Tôrres Aguiar. O estudo das cidades médias brasileiras: uma proposta metodológica. In. SPOSITO, Maria Encarnação Beltrão (org.). Cidades médias: espaços em transição. São Paulo: Expressão Popular, 2007.

VASCONCELLOS, Eduardo Alcântara. Transporte urbano nos países em desenvolvimento. São Paulo: Editoras Unidas, 1996.

VASCONCELLOS, Eduardo Alcântara. Transporte urbano, espaço e equidade: análise das políticas públicas. São Paulo: NetPress, 1998.

XAVIER, Marcos. Os sistemas de engenharia e a tecnicização do território. O exemplo da rede rodoviária brasileira. In. SANTOS, Milton; SILVEIRA, María Laura. O Brasil: território e sociedade no início do século XXI. Rio de Janeiro: Record, 2003. (329 343).

Artigo recebido para publicação em maio de 2014.

Artigo aceito para publicação em dezembro de 2014. 